\title{
Removal of pharmaceuticals in pre-denitrifying MBBR - Influence of organic substrate availability in single- and three-stage configurations
}

Polesel, Fabio; Torresi, Elena; Loreggian, L.; Escola Casas, Monica; Christensson, Magnus; Bester, Kai; Plósz, Benedek G.

Published in:

Water Research

Link to article, DOI:

10.1016/j.watres.2017.06.068

Publication date:

2017

Document Version

Peer reviewed version

Link back to DTU Orbit

Citation (APA):

Polesel, F., Torresi, E., Loreggian, L., Escola Casas, M., Christensson, M., Bester, K., \& Plósz, B. G. (2017).

Removal of pharmaceuticals in pre-denitrifying MBBR - Influence of organic substrate availability in single- and three-stage configurations. Water Research, 123, 408-419. https://doi.org/10.1016/j.watres.2017.06.068

\section{General rights}

Copyright and moral rights for the publications made accessible in the public portal are retained by the authors and/or other copyright owners and it is a condition of accessing publications that users recognise and abide by the legal requirements associated with these rights.

- Users may download and print one copy of any publication from the public portal for the purpose of private study or research.

- You may not further distribute the material or use it for any profit-making activity or commercial gain

- You may freely distribute the URL identifying the publication in the public portal 


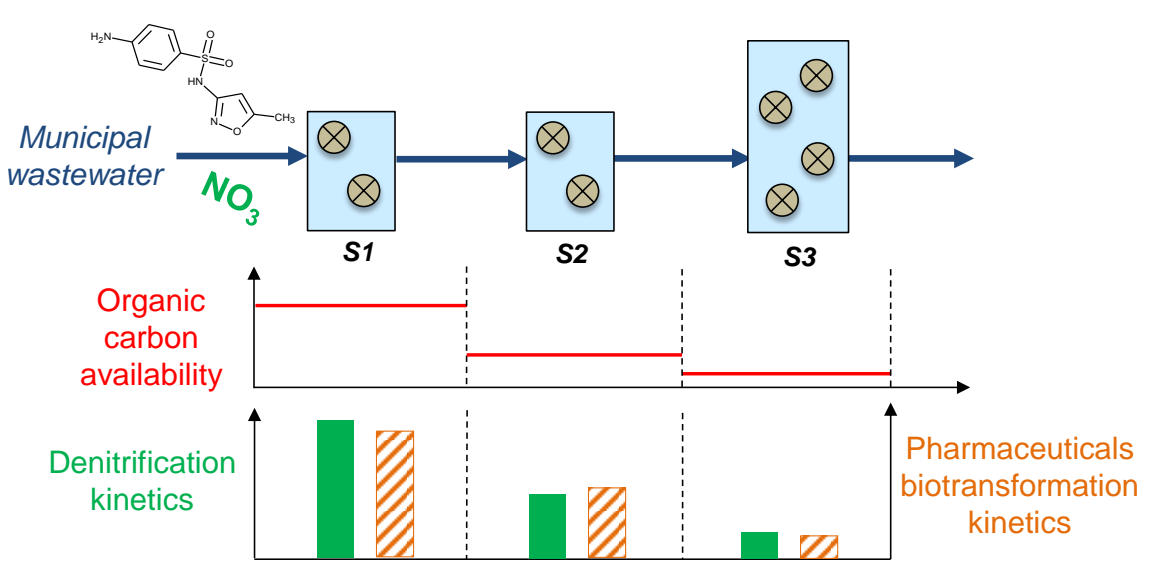


2 Removal of pharmaceuticals in pre-denitrifying MBBR -

3 Influence of organic substrate availability in single- and

\section{three-stage configurations}

6 Fabio Polesel ${ }^{1, *}$, Elena Torresi ${ }^{1,2}$, Luca Loreggian ${ }^{1,3}$, Monica Escolá Casas ${ }^{4}$,

7 Magnus Christensson ${ }^{2}$, Kai Bester ${ }^{4}$, Benedek Gy. Plósz ${ }^{1,5, *}$

8

$9{ }^{1}$ DTU Environment, Technical University of Denmark, Bygningstorvet B115, 2800 Kongens

10 Lyngby, Denmark

$11{ }^{2}$ Veolia Water Technologies AB, AnoxKaldnes, Klosterängsvägen 11A, SE-226 47 Lund,

12 Sweden

$13{ }^{3}$ Environmental Engineering Institute, Ecole Polytechnique Fédérale de Lausanne, Station 6,

141015 Lausanne, Switzerland

$15{ }^{4}$ Department of Environmental Science, Aarhus University, Frederiksborgvej 399, 4000

16 Roskilde, Denmark

$17{ }^{5}$ Department of Chemical Engineering, University of Bath, Claverton Down, Bath BA2 7AY, $18 \mathrm{UK}$

20 Corresponding authors: fabp@env.dtu.dk, b.g.plosz@bath.ac.uk

21 


\section{Abstract}

24 Due to the limited efficiency of conventional biological treatment, innovative solutions are

25 being explored to improve the removal of trace organic chemicals in wastewater. Controlling 26 biomass exposure to growth substrate represents an appealing option for process optimization, 27 as substrate availability likely impacts microbial activity, hence organic trace chemical 28 removal. This study investigated the elimination of pharmaceuticals in pre-denitrifying moving 29 bed biofilm reactors (MBBRs), where biofilm exposure to different organic substrate loading 30 and composition was controlled by reactor staging. A three-stage MBBR and a single-stage 31 reference MBBR (with the same operating volume and filling ratio) were operated under 32 continuous-flow conditions (18 months). Two sets of batch experiments (day 100 and 471) 33 were performed to quantify and compare pharmaceutical removal and denitrification kinetics 34 in the different MBBRs. Experimental results revealed the possible influence of retransformation (e.g., from conjugated metabolites) and enantioselectivity on the removal of selected pharmaceuticals. In the second set of experiments, specific trends in denitrification and biotransformation kinetics were observed, with highest and lowest rates/rate constants in

38 the first (S1) and the last (S3) staged sub-reactors, respectively. These observations were confirmed by removal efficiency data obtained during continuous-flow operation, with limited

40 removal $(<10 \%)$ of recalcitrant pharmaceuticals and highest removal in S1 within the three41 stage MBBR. Notably, biotransformation rate constants obtained for non-recalcitrant 42 pharmaceuticals correlated with mean specific denitrification rates, maximum specific growth 43 rates and observed growth yield values. Overall, these findings suggest that: (i) the long-term 44 exposure to tiered substrate accessibility in the three-stage configuration shaped the 45 denitrification and biotransformation capacity of biofilms, with significant reduction under 46 substrate limitation; (ii) biotransformation of pharmaceuticals may have occurred as a result of 
47 cometabolism by heterotrophic denitrifying bacteria.

48

49 Keywords: Moving bed biofilm reactors, pharmaceutical biodegradation, heterotrophic

50 denitrification, reactor staging, organic substrate 


\section{1. Introduction}

52 Elimination of pharmaceuticals and other trace organic chemicals represents a major challenge

53 in conventional wastewater treatment systems. Innovative solutions, e.g., novel treatment

54 technologies or process configurations, have been explored to improve the removal efficiency

55 in biological wastewater treatment facilities.

56 Among the plethora of evaluated options, staging of biological reactors (defined as the 57 subdivision into two or more completely mixed sub-reactors in series) has been proposed to 58 optimize pollutant removal processes based on reaction kinetic principles (Scuras et al., 2001; 59 Joss et al., 2006; Grady et al., 2011). Staging of pre-denitrifying reactors (Plósz, 2007; Plósz et 60 al., 2010a) was accordingly hypothesized to enhance denitrification as compared to single61 stage configurations. In staged systems with prolonged physical biomass retention (i.e. as biofilms), microbial adaptation to specific substrate availability conditions can be induced in each sub-stage. As to pre-denitrifying systems, shaping of microbial activity and community is

64 determined by the availability and the quality (e.g., in terms of degradability) of electron 65 donating organic substrate. Nevertheless, it is unknown how reactor staging would impact the 66 removal (via biotransformation) of trace organic chemicals. Although it has been hypothesized 67 that the degradation of more recalcitrant organics (such as xenobiotics) would occur in 68 substrate-limited staged denitrifying reactors (Plósz et al., 2010a)—as also observed under 69 aerobic conditions (Escolá Casas et al., 2015)—no evidence is currently available.

70 Recently, moving bed biofilm reactors (MBBRs) have been considered as an option to improve 71 the removal of pharmaceuticals. In MBBRs, biomass grows on suspended plastic carriers 72 (Ødegaard et al., 1994), with expected increase of biomass residence time compared to 73 activated sludge systems. Enhanced biotransformation was accordingly observed in nitrifying 74 MBBRs for a number of pharmaceuticals (Falås et al., 2012, 2013; Torresi et al., 2016). As the 
wide majority of studies have focused on aerobic conditions (in line with overall literature on biodegradation of xenobiotics; Ghattas et al., 2017), little is known about denitrifying MBBRs, with detailed information only recently obtained for post-denitrifying systems (Torresi et al., 2017).

In this study, we investigated the elimination of pharmaceuticals in single-stage and threestage MBBR configurations for pre-denitrification of municipal wastewater. We assessed the effect of organic substrate availability on pharmaceutical degradation and ensured prolonged biomass exposure (via immobilization on carriers) to specific substrate availability conditions. During long-term continuous operation of the two systems, batch experiments were performed at two distinct time points to assess kinetics of heterotrophic denitrification and pharmaceutical removal in each MBBR. Indigenous pharmaceutical concentrations in wastewater media were used in the study, given the potentially significant influence of spiking on transformation kinetics and pathways (Collado et al., 2012; Jewell et al., 2016) as well as the possibility of retransformation from conjugated metabolites and structural analogues (Polesel et al., 2016). The main objectives of our investigation were: (i) to assess and compare kinetics of denitrification (primary metabolic function) and pharmaceutical biotransformation (secondary

91 metabolic function) in different MBBR systems; (ii) to assess the influence of biofilm exposure to different organic substrate loading and complexity, resulting from MBBR staging, on its capability of reducing nitrate and nitrite and biotransforming selected pharmaceuticals; and (iii) to eventually investigate the association between these (primary and secondary) microbial functions. Specifically, two alternative hypotheses were tested:

- Strongly limiting organic substrate availability (in the downstream reactor stages) induces an improvement of pharmaceutical biotransformation kinetics due to the enhanced utilization of recalcitrant chemicals (e.g., pharmaceuticals) as metabolic/ cometabolic 
substrates;

- Non-limiting organic substrate availability (occurring in the upstream reactor stages) positively influences pharmaceutical biotransformation kinetics by more effectively supporting denitrifying activity.

\section{Materials and methods}

\subsection{System description and operation}

Two laboratory scale pre-denitrifying MBBR configurations with K1 carriers (AnoxKaldnes, Lund, Sweden; specific surface area $=500 \mathrm{~m}^{2} \mathrm{~m}^{-3}$ ) were operated in parallel under continuousflow conditions for 1.5 years (Fig. 1). The two configurations were operated under identical conditions, i.e. influent flow rate, hydraulic residence time, influent medium characteristics, to allow for a comparative assessment of system performance.

The single-stage configuration included a single bioreactor (U) with operating volume of $6 \mathrm{~L}$. The three-stage configuration was designed according to principles presented by Plósz (2007) and included three reactors in series (named S1, S2, S3) with a total operating volume of $6 \mathrm{~L}$ (1.5 $\mathrm{L}$ for $\mathrm{S} 1$ and $\mathrm{S} 2$ and $3 \mathrm{~L}$ for $\mathrm{S} 3$ ). To limit $\mathrm{O}_{2}$ penetration, reactors were continuously sparged with $\mathrm{N}_{2}$ gas ( $\geq 99.996 \%$, Aga A/S, Copenhagen, Denmark) and provided with polystyrene lids and rubber top sealing, having a small opening that allowed for sparging gas to escape. These solutions allowed establishing DO concentrations lower than $0.05 \mathrm{mg} \mathrm{L}^{-1}$ in all MBBRs for the duration of the experiment. Sparging of $\mathrm{N}_{2}$ gas was also used for mechanical mixing of K1 carriers.

MBBR carriers with attached biofilm used for reactor seeding were collected from the postdenitrification zone of Sjölunda WWTP (Malmö, Sweden). The post-denitrifying train of Sjölunda WWTP consists of two tanks in series, whereby dosage of external carbon source 
123 (methanol) takes place in the first tank of the treatment train while MBBR carriers (and 124 attached biofilms) were collected from the second tank. A filling ratio of $33 \%$ was selected for 125 all reactors. All MBBRs were operated at ambient temperature.

126 The two configurations were continuously fed with primary wastewater effluent (Mølleåværket 127 WWTP, Lundtofte, Denmark) at an influent flow rate of $15 \mathrm{~L} \mathrm{~d}^{-1}$ for each system. Pre-clarified 128 wastewater was collected semi-weekly, stored in a $200 \mathrm{~L}$ stirred cooling tank $\left(<4^{\circ} \mathrm{C}\right)$ and fed 129 to the MBBR reactors using a peristaltic pump (Ole Dich, Hvidovre, Denmark). Nitrate was 130 supplied to both MBBR systems from a $10 \mathrm{~g} \mathrm{~L}^{-1}$ dosing solution of $\mathrm{KNO}_{3}(\geq 99.9 \%$, Merck 131 Millipore, Darmstadt, Germany), fed at a flow rate of $1.2 \mathrm{~L} \mathrm{~d}^{-1}$ using another peristaltic pump 132 (Ole Dich, Hvidovre, Denmark). The resulting influent nitrate concentration (103 $\mathrm{mgN} \mathrm{L}^{-1}$ ) 133 ensured that there was sufficient residual nitrate in the treated effluent, thereby allowing for 134 denitrification to occur in all the MBBRs (which could permanently operate under anoxic 135 conditions). As in full-scale pre-denitrifying systems, the indigenous COD content of pre136 clarified wastewater was the only electron donor available for denitrification, i.e. no extra 137 carbon source was supplied. Furthermore, during the entire operation period both systems 138 received only indigenous pharmaceutical concentrations present in the feeding medium.

139 The two MBBR systems were monitored during continuous-flow operation for approximately 1401.5 months before and/or after batch experiments (see section 2.2). System performance in 141 terms of heterotrophic denitrification and pharmaceutical removal was assessed by monitoring 142 influent and effluent concentrations of $\mathrm{COD}, \mathrm{NO}_{3}-\mathrm{N}, \mathrm{NO}_{2}-\mathrm{N}$ and pharmaceuticals (see section 143 S4, Table S5). Characterization of organic carbon in the influent wastewater was carried out 144 according to Roeleveld and van Loosdrecht (2002). 


\subsection{Batch experiments}

\subsubsection{Biotic}

149 Batch experiments were performed to assess biokinetics of heterotrophic denitrification and 150 pharmaceuticals elimination in the four MBBRs (U, S1, S2, S3). Two sets of batch 151 experiments were performed during 1.5 year of continuous operation: Batch 1 (day 100) and 152 Batch 2 (day 471). In both cases, the continuous MBBR systems were disconnected and 153 experiments were performed with carriers from U, S1, S2 and S3 separately at the same 154 boundary and initial conditions (feeding medium characteristics, filling ratio, reactor operation).

156 Similarly to continuous-flow operation, pre-clarified wastewater from Mølleåværket WWTP 157 was used as feeding medium in batch experiments. The medium was supplemented with $\mathrm{KNO}_{3}$, 158 resulting in an initial $\mathrm{NO}_{3}-\mathrm{N}$ concentration of $100-104 \mathrm{mgN} \mathrm{L}^{-1}$. DO concentration was 159 minimized through continuous sparging of $\mathrm{N}_{2}$ gas. Temperature and $\mathrm{pH}$ were continuously monitored (SenTix ${ }^{\circledR}$ 980, WTW, Weilheim, Germany). Manual pH adjustment with $1 \mathrm{M} \mathrm{HCl}$

161 was performed at the beginning and through the experiment to prevent microbial activity 162 inhibition. Experiments were performed at ambient temperature. Spiking of reference 163 pharmaceuticals was not used, and only the indigenous chemicals occurring in pre-clarified 164 wastewater were quantified. Aqueous samples for the analysis of pharmaceuticals and conventional pollutants were withdrawn from MBBRs and concurrently a fixed number of 166 carriers were removed to maintain a constant filling ratio.

167 The duration of Batch 1 was $24 \mathrm{~h}$, with MBBR filling adjusted to $20 \%$. The temperature during 168 batch experiments was (mean and standard deviation, 5 min frequency): $20.3 \pm 0.9^{\circ} \mathrm{C}$ for $\mathrm{S} 1$, $16920.2 \pm 1.3^{\circ} \mathrm{C}$ for $\mathrm{S} 2,20.3 \pm 1.0^{\circ} \mathrm{C}$ for $\mathrm{S} 3,20.3 \pm 0.9^{\circ} \mathrm{C}$ for $\mathrm{U}$. In Batch 2 , a filling ratio of $10 \%$ 170 was used and the experiment duration was extended to $49 \mathrm{~h}$. The temperature during batch 
171 experiments was (mean and standard deviation, 10 min frequency): $16.7 \pm 0.5^{\circ} \mathrm{C}$ for $\mathrm{S} 1,17.4 \pm$ $0.5^{\circ} \mathrm{C}$ for $\mathrm{S} 2,16.8 \pm 0.4^{\circ} \mathrm{C}$ for $\mathrm{S} 3,17.0 \pm 0.5^{\circ} \mathrm{C}$ for $\mathrm{U}$.

\subsubsection{Control experiments}

175 A reference batch experiment (abiotic control experiment) was additionally performed to 176 assess abiotic degradation of pharmaceuticals, based on the methodology proposed by Falås et 177 al. (2013). The experiment was conducted in a glass container with $200 \mathrm{~mL}$ pre-filtered (GF 178 filter, $0.6 \mu \mathrm{m}$ pore size, Advantec, Knebel, Denmark) pre-clarified wastewater (Mølleåværket 179 WWTP, Lundtofte, Denmark). Reactor mixing was ensured by $\mathrm{N}_{2}$ gas sparging. The 180 experiment was conducted in the absence (first $2 \mathrm{~h}$ ) and in the presence of plastic carriers 181 without biofilm (last $2 \mathrm{~h}$ ), with an overall duration of $4 \mathrm{~h}$. Aqueous samples were withdrawn at $182 \mathrm{t}=0,2$ and $4 \mathrm{~h}$. An evaporation control experiment was additionally carried out in parallel to 183 assess the evaporation of filtered wastewater due to $\mathrm{N}_{2}$ gas sparging. Two glass containers 184 (working volume $=200 \mathrm{~mL}$ ) were operated in parallel and under the same conditions of the 185 reference control experiment. Residual liquid volume was measured in the two reactors after 2 $186 \mathrm{~h}$ and $4 \mathrm{~h}$, respectively.

\subsection{Analytical methods}

189 Samples for the analysis of conventional pollutants were collected and analysed for total and 190 soluble $\mathrm{COD}, \mathrm{NO}_{3}-\mathrm{N}$ and $\mathrm{NO}_{2}-\mathrm{N}$. Non-filtered and filtered samples $(0.45 \mu \mathrm{m}$ GF filters; 191 Sartorius, Göttingen, Germany) were stored in plastic vials at $\leq 4{ }^{\circ} \mathrm{C}$ until analysis (for non192 filtered samples, within $24 \mathrm{~h}$ from collection). COD concentrations were quantified using 193 Hach-Lange colorimetric kits (LCK314, LCK514) and Hach-Lange DR 2800 194 spectrophotometer. $\mathrm{NO}_{3}-\mathrm{N}$ and $\mathrm{NO}_{2}-\mathrm{N}$ concentrations were quantified with Merck colorimetric 
195 kits and subsequent spectrophotometric quantification (Batch 1) or with a Bran Luebbe® Auto 196 Analyzer 3 digital colorimeter (Batch 2).

197 The concentration of attached biomass was determined from the weight difference of multiple $198(\geq 5)$ dried carriers $\left(105^{\circ} \mathrm{C}\right.$ for $\left.>1 \mathrm{~h}\right)$ before and after biofilm removal, as described in Falås et 199 al. (2012). Attached biofilm was removed from plastic carriers using $\mathrm{H}_{2} \mathrm{SO}_{4}(4 \mathrm{M})$ and thorough 200 brushing. The resulting biomass concentration was expressed in terms of total attached solids 201 (gTAS L ${ }^{-1}$ ). Conversion factors TSS/TAS and VSS/TAS for biofilm in each MBBR were 202 determined via parallel measurements of TAS, TSS and VSS content. Biofilm from five 203 carriers for each MBBR was detached and resuspended in $50 \mathrm{~mL}$ tap water. Four replicate 204 measurements were performed, with overall biofilm detachment from 20 carriers per MBBR. 205 TAS (in analogy with total solids), TSS and VSS concentrations of the suspension were 206 measured according to APHA standard methods (Clesceri et al., 1998). Determination of 207 TSS/TAS ratio allowed converting attached biomass concentration to gTSS $\mathrm{L}^{-1}$. The overall 208 TSS concentration in each MBBR was eventually determined by accounting for TSS in bulk 209 aqueous phase (separate measurement according to APHA standard methods).

210 Samples for pharmaceutical analysis were collected and prepared according to the procedure 211 described by Escolá Casas et al. (2015). Briefly, $4 \mathrm{ml}$ wastewater samples were collected and 212 stored in glass vials (Chromacol $22 \mathrm{~mL}$, Mikrolab, Aarhus, Denmark). $1.4 \mathrm{ml}$ pure methanol ( $\geq$ 213 99.9\%, Merck Millipore) was added to inhibit biological activity during the storage period. 214 Prepared samples were then preserved at $-20^{\circ} \mathrm{C}$. Subsequently, $1.5 \mathrm{~mL}$ was of each sample 215 were transferred to an HPLC vial and were centrifuged (6000 rpm, 10 minutes) to separate 216 residual solids. $900 \mu \mathrm{L}$ of the supernatant were transferred to a new vial, to which $100 \mu \mathrm{L}$ of 217 internal standard solution were added using a glass syringe. Samples were analyzed using 218 HPLC-MS/MS with an injected volume of $100 \mu \mathrm{L}$. Twenty-three active pharmaceutical 
219 substances, typically present in wastewater influents, were targeted. A complete list of these

220 substances is given in the Supporting Information (section S4) and elsewhere (Escolá Casas et

221 al., 2015). Specifications of the HPLC-MS/MS analytical device and of the internal standard 222 solution can be found in Escolá Casas et al. (2015).

\subsection{Anoxic respirometry}

225 In Batch 1 and 2, heterotrophic denitrification was assessed by measuring $\mathrm{NO}_{3}-\mathrm{N}$ and $\mathrm{NO}_{2}-\mathrm{N}$ $226\left(\mathrm{mgN} \mathrm{L}^{-1}\right)$ concentrations in different MBBRs. $\mathrm{NO}_{2}-\mathrm{N}$ concentration was measured due to the 227 possibility of nitrite accumulation, as shown in previous experiments (Ubay Çokgör et al., 1998; 228 Kujawa and Klapwijk, 1999; Ekama and Wentzel, 1999), thus being accounted for when 229 characterizing denitrification kinetics. Based on measured $\mathrm{NO}_{3}-\mathrm{N}$ and $\mathrm{NO}_{2}-\mathrm{N}$ concentrations, 230 anoxic respirograms were derived for each batch experiment as $\mathrm{NO}_{\mathrm{X}}$ utilization curves, where $231 \mathrm{NO}_{\mathrm{X}^{-}} \mathrm{N}$ concentration $\left(\mathrm{mgN} \mathrm{L}^{-1}\right)$ was calculated according to Eq. 1 (Ubay Çokgör et al., 1998):

$232 \quad \mathrm{NO}_{X}-\mathrm{N}=\mathrm{NO}_{3}-\mathrm{N}+0.6 \mathrm{NO}_{2}-\mathrm{N}$

233 In this equation, the coefficient 0.6 denotes the relative amount of electrons required to reduce $234 \mathrm{NO}_{2}$ to $\mathrm{N}_{2}\left(3 \mathrm{e}^{-}\right)$compared to the reduction of $\mathrm{NO}_{3}$ to $\mathrm{N}_{2}\left(5 \mathrm{e}^{-}\right)$. It is anticipated that two 235 distinct $\mathrm{NO}_{\mathrm{X}}$ utilization rates could be distinguished during batch experiments (Fig. S5). Fast 236 slow specific denitrification rates $\left(k_{1}\right.$ and $k_{2}$, respectively; $\left.\operatorname{mgN} \operatorname{gTSS}^{-1} \mathrm{~d}^{-1}\right)$ were accordingly 237 derived in each MBBR through linear regression of $\mathrm{NO}_{\mathrm{X}}$ concentrations and normalization to 238 biomass concentration (as gTSS $\mathrm{L}^{-1}$ ). In order to provide for a unique kinetic descriptor of 239 denitrification, the mean specific denitrification rate $\bar{k}_{\text {Nox }}\left(\mathrm{mgN} \mathrm{gTSS}^{-1} \mathrm{~d}^{-1}\right)$ was calculated 240 (Eq. 2):

$241 \bar{k}_{N O X}=\frac{k_{1}+k_{2}}{2}$ 
242 Surface-normalized mean denitrification rates $\left(\bar{r}_{N O X}, r_{1}\right.$ and $\left.r_{2}, \mathrm{gN} \mathrm{m}^{-2} \mathrm{~d}^{-1}\right)$ were also derived

243 for each MBBR. The rationale for the interpretation of anoxic respirometric data, as well as the 244 definition of denitrification rates, is described in detailed in the Supporting Information 245 (section S3).

\subsection{Modelling pharmaceutical removal kinetics}

248 Based on observations on pharmaceutical removal in Batch 1 and 2, model structures were 249 identified using the Activated Sludge Model framework for Xenobiotics (ASM-X) (Plósz et al., 250 2010b, 2012), including recent extensions presented by Torresi et al. (2017). A summary of 251 identified model structures is shown in Table 1.

252 In the simplest model structure, pseudo-first-order degradation kinetics was used to describe 253 aqueous concentration decrease (Eq. 3)

$254 \quad \frac{d C_{L I}}{d t}=-\frac{k_{b i o}}{\left(1+K_{d} X_{T S S}\right)} C_{L I} X_{T S S}$

255 where $C_{L I}$ denotes the aqueous pharmaceutical concentration (ng $\left.\mathrm{L}^{-1}\right), k_{b i o}$ the 256 biotransformation rate constant $\left(\mathrm{L} \mathrm{gTSS}^{-1} \mathrm{~d}^{-1}\right)$ and $X_{T S S}$ the biomass concentration in MBBRs $257\left(\mathrm{gTSS} \mathrm{L}^{-1}\right)$. A correction factor for sorption was considered, where $K_{d}\left(\mathrm{~L} \mathrm{~g}^{-1}\right)$ denotes the 258 sorption coefficient, assuming instantaneous equilibrium between aqueous and sorbed 259 concentrations (Joss et al., 2006). Constant $X_{T S S}$ was assumed, considering negligible biomass 260 growth during batch experiments. The effect of diffusion into biofilm on the removal of 261 pharmaceuticals from bulk aqueous phase was lumped in the biotransformation rate constants 262 (Falås et al., 2012, 2013; Escolá Casas et al., 2015; Torresi et al., 2016, 2017).

263 The transformation of human metabolites and other fractions (Polesel et al., 2016) may lead to 264 the formation of parent compounds and can be additionally described using pseudo-first-order 265 kinetics (Eq. 4): 
$266 \frac{d C_{C J}}{d t}=-k_{d e c} C_{C J} X_{T S S}$

267 where the state variable $C_{C J}$ denotes the retransformable pharmaceutical fractions (e.g., 268 conjugated metabolites) and $k_{d e c}\left(\mathrm{~L} \mathrm{gTSS}^{-1} \mathrm{~d}^{-1}\right)$ denotes the retransformation rate constant. 269 Negligible sorption was considered for the fraction $C_{C J}$ due to its potentially high 270 hydrophilicity (Göbel et al., 2005; Plósz et al., 2010b). Simultaneous parent compound 271 formation and biotransformation were thus described using Eq. 5:

$272 \frac{d C_{L I}}{d t}=-\frac{k_{\text {bio }}}{\left(1+K_{d} X_{T S S}\right)} C_{L I} X_{T S S}+k_{d e c} C_{C J} X_{T S S}$

273 or, in case of only one major conjugated metabolite, using Eq. 6:

$\frac{d C_{L I}}{d t}=-\frac{k_{\text {bio }}}{\left(1+K_{d} X_{T S S}\right)} C_{L I} X_{T S S}+\frac{M_{L I}}{M_{C J}} k_{d e c} C_{C J} X_{T S S}$

275 where $M_{L I}$ and $M_{C J}\left(\mathrm{~g} \mathrm{~mol}^{-1}\right)$ denote the molecular mass of the parent compound and the 276 conjugate, respectively, and their ratio denotes the stoichiometry coefficient of 277 retransformation (Plósz et al., 2013; Torresi et al., 2017).

\subsection{Parameter estimation}

280 Estimation of transformation rate constants $\left(k_{b i o}, k_{d e c}\right)$ required the initial assumption of $K_{d}$. 281 Values measured in activated sludge—where available under denitrifying conditions—-were 282 collected from published literature (Ternes et al., 2004; Göbel et al., 2005; Maurer et al., 2007; 283 Radjenovic et al., 2009; Wick et al., 2009; Plósz et al., 2010b; Hörsing et al., 2011; Plósz et 284 al., 2012). In absence of published $K_{d}$ values, negligible sorption was assumed. Table S6 285 summarizes $K_{d}$ values for detected pharmaceuticals.

286 When parent compound formation was observed in the absence of $C_{C J}$ measurements, the 287 initial concentration $C_{C J, O}\left(\mathrm{ng} \mathrm{L}^{-1}\right)$ was defined by assuming the same initial ratio $n_{L I, C J}$ (Eq. 7) 
288 in all simultaneous batch experiments:

$289 n_{L I, C J}=\frac{C_{L I, 0}}{C_{C J, 0}}$

290 where $C_{L I, 0}$ denotes the initial parent compound concentration $\left(\mathrm{ng} \mathrm{L}^{-1}\right)$. In this case, calibration

291 of Eq. 5 was performed for all experiments simultaneous, also with the estimation of $n_{L I, C J}$.

292 In all cases, model calibration against experimental data in Batch 1 and 2 was performed using 293 the secant method embedded in Aquasim 2.1d (Reichert, 1998). Surface-normalized 294 transformation rate constants $\left(\mathrm{L}^{-1} \mathrm{~m}^{-2} \mathrm{~d}^{-1}\right)$ were eventually calculated from estimated $k_{b i o}$ and $295 k_{d e c}$ values. 
3. Results and discussion

\subsection{Heterotrophic denitrification}

\subsubsection{Monitoring during continuous-flow operation}

300 Due to considerable fluctuations in the quality of the wastewater influent, dynamics in $\mathrm{NO}_{\mathrm{X}}$ 301 removal were shown (Table S1, Fig. S2). Variability was observed in terms of influent 302 concentrations of total COD $\left(207 \pm 57 \mathrm{mgCOD} \mathrm{L}^{-1}\right)$, soluble COD $\left(84 \pm 26 \mathrm{mgCOD} \mathrm{L}^{-1}\right)$, 303 biodegradable COD $\left(136 \pm 42 \mathrm{mgCOD} \mathrm{L}^{-1}\right)$, readily biodegradable COD $\left(S_{S}, 61 \pm 25 \mathrm{mgCOD}\right.$ $\left.304 \mathrm{~L}^{-1}\right)$ and hydrolizable $\mathrm{COD}\left(X_{S}, 75 \pm 37 \mathrm{mgCOD} \mathrm{L}^{-1}\right)$. $\mathrm{NO}_{\mathrm{X}}$ removal per influent total COD was 305 calculated, being $0.15-0.18 \mathrm{mgNO}_{\mathrm{X}}-\mathrm{N} \mathrm{mgCOD}^{-1}$ for three-stage $\mathrm{MBBR}$ and $0.12-0.16$ $306 \mathrm{mgNO}_{\mathrm{X}}-\mathrm{N} \mathrm{mgCOD}{ }^{-1}$ for single-stage MBBR (Table S2). $\mathrm{NO}_{2}-\mathrm{N}$ accumulation in the MBBR 307 reactors was accounted for when calculating $\mathrm{NO}_{\mathrm{X}}$ removal as shown in Eq. 1.

308 Surface-normalized $\mathrm{NO}_{\mathrm{X}}$ removal rates exhibited a significant decrease after 400 days of 309 operation (Table S2). This may be attributed to the reduced average influent loading of organic 310 substrate (before day 100: $3.95 \pm 0.87 \mathrm{gCOD} \mathrm{d}^{-1}$; after day 400: $2.66 \pm 0.41 \mathrm{gCOD} \mathrm{d}^{-1}$; here 311 expressed as total COD).

312 Reactor staging effectively determined a declining gradient of influent substrate loading from 313 S1 to S3 (Table S3). Temporal trends of attached biomass concentration $\left(\mathrm{gTAS} \mathrm{L}^{-1}\right.$ ) in each 314 MBBR indicated significant growth as compared to the inoculum (Fig. S1). Faster growth was 315 observed in S1, with stable biomass concentration reached after approximately 80 days, as 316 compared to the other reactors (> $100 \mathrm{~d}$ ). Towards the end of the operation period, the highest 317 biomass concentration was found in S2 $\left(5.2 \mathrm{gTAS} \mathrm{L}^{-1}\right)$ and comparable concentrations were 318 found in the other MBBRs (3.9-4.2 gTAS L $\left.^{-1}\right)$. 
321 Measured concentration profiles of $\mathrm{NO}_{3}-\mathrm{N}, \mathrm{NO}_{2}-\mathrm{N}$, total and soluble COD are presented in

322 Fig. S3 (Batch 1) and Fig. S4 (Batch 2). In all experiments, $\mathrm{NO}_{2}-\mathrm{N}$ accumulation was

323 observed, being more prominent in Batch 2 (up to $10 \mathrm{mgN} \mathrm{L}^{-1}$ in $\mathrm{S} 3$ ). The residual soluble

324 COD concentration was found comparable $\left(53 \pm 3 \mathrm{mgCOD} \mathrm{L}^{-1}\right.$ in Batch $1 ; 54 \pm 7$ in Batch 2),

325 representing the inert organic matter not utilizable as electron donor.

326 In Batch 1, depletion of organic substrate in the wastewater medium (based on soluble COD 327 measurements) was reached after 0.2-0.4 d, typically coinciding (except for S3) with a change 328 in $\mathrm{NO}_{\mathrm{X}}$ reduction rate (Fig. S5a). As to $\mathrm{NO}_{\mathrm{X}}$ reduction kinetics, no trend was shown for $\bar{k}_{\text {NOX }}$ 329 in the three staged MBBRs (Table S4).

330 A number of peculiar observations were made during Batch 2, which will be thus discussed 331 more in detail. Figure 2 presents measured concentration profiles of $\mathrm{NO}_{\mathrm{X}}$ (a) and total COD (b) 332 in the different MBBRs during Batch 2. Experimental data revealed significantly different 333 denitrification capacity and kinetics in MBBRs. Notably, initial lag phases in $\mathrm{NO}_{\mathrm{X}}$ reduction 334 were found in S2, U (1.5 h) and S3 (3 h) (Fig. 2a), possibly resulting from the prior limited 335 exposure of biofilm in these MBBRs to readily biodegradable organic substrate. As to S2 and 336 S3, this indicates that the three-staged reactor design achieved exposing biofilm to limiting and 337 highly limiting organic substrate, respectively (Plósz, 2007). Furthermore, $\mathrm{NO}_{\mathrm{X}}$ reduction 338 during continuous-flow operation predominantly relied on hydrolysis products also in the 339 single-stage system U.

$340 \mathrm{NO}_{\mathrm{X}}$ reduction rates were determined by neglecting the initial lag phase (Fig. S5). Calculated $341 \bar{k}_{\text {NoX }}$ values were $48.2 \mathrm{mgN} \mathrm{gTSS}^{-1}$ for S1, $18.9 \mathrm{mgN} \mathrm{gTSS}^{-1}$ for S2, $12.4 \mathrm{mgN} \mathrm{gTSS}^{-1}$ for S3 342 and $20.3 \mathrm{mgN} \mathrm{gTSS}^{-1}$ for $\mathrm{U}$. When considering the three-stage system, $\bar{k}_{\text {Nox }}$ (and the surface343 normalized rate $\bar{r}_{N O X}$ ) declined from S1 to S3, indicating that different organic substrate 344 loading and availability influenced both the capacity and the kinetics of $\mathrm{NO}_{\mathrm{X}}$ reduction in 
345 MBBR biofilm. A substantial decrease of $\bar{k}_{N O X}$ and $\bar{r}_{\text {NOX }}$ was observed in Batch 2 as

346 compared to Batch 1 (Table S4), being more pronounced in S2, S3 and U. Not unexpectedly,

347 both biomass- and surface-normalized rates were significantly lower than in post-denitrifying

348 MBBRs, where only easily degradable external organic substrate is used as electron donor

349 (Torresi et al., 2017).

350 Different levels of $\mathrm{NO}_{\mathrm{X}}$ reduction were achieved in all MBBRs with comparable total COD 351 removal $\left(\triangle \mathrm{COD}=257-275 \mathrm{mgCOD} \mathrm{L}^{-1}\right.$ over $\left.48 \mathrm{~h}\right)$ and utilization kinetics (Fig. 2b). 352 Accordingly, COD storage may have occurred in S2, S3 and U due to biofilm exposure to feast 353 substrate availability conditions following prolonged famine during continuous-flow operation, 354 as previously shown for denitrifying bacteria (Beun et al., 2000). The microbial growth yield, $355 Y_{H}\left(\mathrm{mgCOD}_{\mathrm{mgCOD}}{ }^{-1}\right)$, was thus calculated based on measured $\mathrm{NO}_{\mathrm{X}}$ and COD concentrations. 356 The calculation of $Y_{H}$ (Eq. 8) was based on $\mathrm{NO}_{\mathrm{X}}$ and COD utilization during fast denitrification 357 (without considering the initial lag phase in S2, S3 and U), thus better approximating the true 358 yield:

$Y_{H}=1-\frac{2.86 \cdot \Delta N O_{X}}{\Delta C O D}$

360 where $2.86\left(\mathrm{mgCOD}_{\mathrm{mgN}}{ }^{-1}\right)$ denotes the $\mathrm{COD}$ equivalents of $\mathrm{NO}_{\mathrm{X}}-\mathrm{N}$ (with the reduced number 361 of COD equivalents of $\mathrm{NO}_{2}-\mathrm{N}$ accounted for in Eq. 1). $\Delta \mathrm{NO}_{\mathrm{X}}\left(\mathrm{mgN} \mathrm{L}^{-1}\right)$ and $\Delta \mathrm{COD}(\mathrm{mgCOD}$ $362 \mathrm{~L}^{-1}$ ) denote the $\mathrm{NO}_{\mathrm{X}}$ and total COD utilized during fast denitrification in Batch 2, respectively, 363 and were quantified using an intercept-based method. Further details on the method (and 364 examples for S1 and S3) are provided in Fig. S6. A value of 0.53 was calculated for $Y_{H}$ in S1, 365 in agreement with typical values for denitrification (Ubay Çokgör et al., 1998). Higher $Y_{H}$ 366 values were instead found for $S 2, S 3$ and $U$ (0.61, 0.77 and 0.67 , respectively), further 367 suggesting the occurrence of substrate storage in these MBBRs (Muller et al., 2003). 
368 Furthermore, maximum specific growth rates $\left(\mu_{\max }\right)$ in each MBBR were derived from the fast 369 denitrification rate $k_{1}$ (using the calculated yield $Y_{H}$ ), according to the method proposed by 370 Ekama and Wentzel (2008). Estimated $\mu_{\max }$ values were 0.22, 0.12, 0.16 and $0.17 \mathrm{~d}^{-1}$ in $\mathrm{S} 1, \mathrm{~S} 2$, 371 S3 and U, respectively. These values were lower than that estimated for nitrate and nitrite 372 reduction in activated sludge using single organic substrate (Pan et al., 2015), but were in 373 agreement with estimations for ethanol-fed post-denitrifying MBBR (Torresi et al., 2017). It 374 should be noted that the presented values may include (for S2, U and especially S3) both the rates of growth and simultaneous substrate storage.

\subsection{Removal of pharmaceuticals}

Based on measured concentrations during continuous-flow operation and in Batch 1 and 2, it was possible to characterize the removal of a number of substances, namely: (i) the betablockers atenolol (ATN) and metoprolol (MET); (ii) the sulfonamide antibiotics sulfamethoxazole (SMX), sulfamethizole (SMZ), sulfadiazine (SDZ) and its conjugated metabolite acetyl-sulfadiazine (AcSDZ), and the combination product trimethoprim (TMP); the macrolides antibiotic erythromycin (ERY); (iv) the anti-inflammatory pharmaceuticals diclofenac (DCF) and ibuprofen (IBU); (v) the X-ray contrast medium iohexol (IOH); (vi) and 386 the anti-depressants citalopram (CIT) and venlafaxine (VFX). Since only indigenous concentrations were considered (i.e., no spiking of reference substances was performed), this is only a sub-sample of the initially targeted pharmaceuticals. Further details on the quantified 389 chemicals can be found in Table S5. In the following sections, results will be thus presented 390 and discussed for the listed substances. 
393 Negligible $(\leq 15 \%)$ or no removal was observed in the abiotic control experiment (Fig. S11), in 394 agreement with previous studies (Falås et al., 2012, 2013; Torresi et al., 2016). For almost all 395 substances (ATN, DCF, IOH, IBU, MET, SMZ, SDZ, AcSDZ, TMP, VFX), an increase of 396 aqueous concentration (on average $+16 \%$ ) was observed and could be attributed to wastewater 397 evaporation during the evaporation control experiment (Fig. S12).

\subsubsection{Biotransformation kinetics (Batch 1 and 2)}

400 Measured pharmaceutical concentrations in Batch 1 and 2 exhibited a number of typical 401 patterns (Fig. 3), which could be interpreted in most cases using Eq. 3-6. A complete overview 402 of measured concentration profiles in both batch experiments is given in Fig. S7-8. Differently 403 from $\mathrm{NO}_{\mathrm{X}}$ reduction, no lag phase in the removal of pharmaceuticals was shown in Batch 2.

404 Several pharmaceuticals (TMP in Batch 1; ATN, ERY, IBU, IOH, SMZ, TMP and VFX in 405 Batch 2) exhibited elimination as in Figure 3a, following pseudo-first-order kinetics (Eq. 3) 406 that were described by $k_{b i o}$.

407 Initial increase of aqueous concentration was observed for SMX, SDZ, DCF and MET (Fig. $4083 b-c)$. Retransformation of these pharmaceuticals can occur from conjugated metabolites, 409 structural analogues and/or parent pharmaceuticals (Polesel et al., 2016) and was considered to 410 explain these profiles. SMX is excreted in the form of parent and two major conjugated 411 metabolites, $\mathrm{N}_{4}$-acetyl-SMX and SMX-N ${ }_{1}$-glucuronide (Vree et al., 1995; van der Ven et al., 412 1995), which were shown to transform back to parent SMX in laboratory- and full-scale 413 studies (Göbel et al., 2005; Plósz et al., 2010; Radke et al., 2009; Stadler et al., 2015). SDZ is 414 known to have only one major conjugated metabolite, AcSDZ (Vree and Hekster, 1987), which 415 could also be quantified during Batch 1 (Fig S6e-f). Eq. 4 and 6 were thus simultaneously 416 calibrated to AcSDZ and SDZ measurements, respectively, allowing for the estimation of $k_{d e c}$ 
417 and $k_{\text {bio. }}$ DCF is also excreted as sulfate and glucuronide conjugates (Stierlin and Faigle, 418 1979), and its formation was reported in laboratory experiments (Lee et al., 2012) and in full419 scale WWTPs (Zhang et al., 2008; Plósz et al., 2012; Vieno and Sillanpää, 2014). As to MET, 420 excretion as conjugated metabolite is negligible (Escher et al., 2006). Formation of MET was 421 still observed in pilot- and full-scale WWTPs (Bendz et al., 2005; Radjenovic et al., 2009; 422 Wick et al., 2009; de Graaff et al., 2011; Jelic et al., 2011). Although these observations have 423 been attributed to sampling and/or analytical uncertainties (Alder et al., 2010), formation from 424 a structurally analogue chemical may not be excluded (in particular under denitrifying 425 conditions).

426 In two cases (ATN in Batch 1, CIT in Batch 2), Eq. 3 did not adequately describe batch 427 removal kinetics. Notably, ATN and CIT are chiral and both enantiomers are present in 428 wastewater (Kasprzyk-Hordern and Baker, 2011; Evans et al., 2015). Similar observations 429 were made for another chiral pharmaceutical, propranolol (Escolá Casas et al., 2015). In 430 analogy with the latter study, enantioselective biotransformation was hypothesized to 431 determine the two-rate profile observed in batch experiments in all four MBBRs (Fig. 3d). 432 Pseudo-first-order transformation kinetics was assumed for the two enantiomers, being 433 described by rate constants $k_{b i o, 1}$ and $k_{b i o, 2}\left(\mathrm{~L} \mathrm{gTSS}^{-1} \mathrm{~d}^{-1}\right)$. Biotransformation of ATN and CIT 434 was thus described according to Eq. 9 (Table 1):

$435 \quad \frac{d C_{L I}}{d t}=-\frac{1}{\left(1+K_{d} X_{T S S}\right)}\left(k_{b i o, 1} C_{E N, 1}+k_{b i o, 2} C_{E N, 2}\right) X_{T S S}$

436 where $C_{E N, 1}$ and $C_{E N, 2}\left(\mathrm{ng} \mathrm{L}^{-1}\right)$ denote the aqueous concentrations of the two enantiomers, 437 respectively, and $C_{L I}\left(\mathrm{ng} \mathrm{L}^{-1}\right)$ is the sum of $C_{E N, 1}$ and $C_{E N, 2}$. Initial conditions for $C_{E N, 1}$ and $438 C_{E N, 2}$ were set by considering in all simultaneous batch experiments the same initial 439 enantiomeric fraction EF (Ribeiro et al., 2013; Eq. 10): 
$E F=\frac{C_{E N, 1}(t=0)}{C_{E N, 1}(t=0)+C_{E N, 2}(t=0)}=\frac{C_{E N, 1}(t=0)}{C_{L I}(t=0)}$

441 Through calibration of Eq. 9 to all batch experiments simultaneously, the parameters $k_{b i o, l}$, $442 k_{b i o, 2}$ and EF could be estimated. The enantioselective biotransformation model (Fig. 3d; Fig. 443 S7a and S8k) was shown to significantly improve the prediction of measured concentrations 444 for ATN and CIT $\left(\mathrm{R}^{2}=0.95-0.99\right)$ as compared to a simple first-order equation (Fig. S9). 445 Nevertheless, this hypothesis requires further confirmation, with identification and 446 quantification of the two enantiomers of ATN and CIT.

\section{< Figure 3 >}

448 Estimated rate constants $\left(k_{b i o}, k_{d e c}, k_{b i o, 1}, k_{b i o, 2}\right)$ in Batch 1 and 2 are presented in Fig. 4 (a and 449 b, respectively). In Table 2, rate constants from this study are compared with literature values 450 for denitrifying activated sludge (DNAS), nitrifying MBBR (NMBBR) and post-denitrifying 451 MBBR (DNMBBR).

452 In Batch 1, the highest rate constant values were estimated either for S1 or U (Fig. 4a), while 453 no overall trend could be identified when considering staged MBBRs only. All the quantifiable 454 pharmaceuticals exhibited comparably high transformation and formation kinetics with the 455 exception of DCF. Rapid retransformation was shown, with $k_{d e c}$ typically higher than $1 \mathrm{~L} \mathrm{~g}^{-1}$ $456 \mathrm{TSS}^{-1}$ and in agreement with previously observed formation (e.g., via deconjugation) kinetics 457 for diclofenac and sulfonamide antibiotics in activated sludge (Plósz et al., 2010b, 2012; Falås 458 et al., 2013) and MBBRs (Falås et al., 2013; Torresi et al., 2016, 2017).

459 In Batch 2, the highest transformation rate constants were observed in S1 for all non460 recalcitrant pharmaceuticals (exhibiting $k_{b i o}, k_{d e c} \geq 0.1 \mathrm{~L} \mathrm{gTSS}^{-1} \mathrm{~d}^{-1}$, according to the 461 classification presented in Joss et al., 2006), with the exception of ATN. An overall decrease of 462 the biotransformation kinetics in U was shown compared to Batch 1. Notably, the order of rate 
463 constant values in staged MBBRs was consistently found to be S1>S2>S3 for all non-

464 recalcitrant compounds, following the gradient of (i) denitrification rates $\bar{k}_{\text {NOx }}$ observed in the 465 same batch; and (ii) loading and complexity of available organic substrate during continuous466 flow operation. Given that all MBBRs had the same specific surface area, the same 467 consideration was valid for surface-normalized biotransformation rate constants (Fig. S10).

468 In analogy with our study, decreasing influent COD loading was found to negatively influence 469 the removal efficiency of the estrogen E1 under aerobic conditions (Tan et al., 2013). The 470 relationship between pharmaceutical transformation and heterotrophic denitrification kinetics 471 will be discussed more in detail in section 3.3.

473 Enhanced biotransformation kinetics, as compared to previous findings in DNAS were shown 474 for SMX, ATN and ERY (Table 2). In particular, $k_{\text {bio }}$ values higher than $1.0 \mathrm{~L} \mathrm{gTSS}^{-1} \mathrm{~d}^{-1}$ were 475 found in $\mathrm{S} 1$, thus indicating a significant increase in biotransformation kinetics for MBBR 476 biofilm growing under non-limiting COD loading. Comparably high transformation kinetics 477 was also shown for SMX and ATN in DNMBBR, in the presence of methanol or ethanol was 478 as electron donor (Torresi et al., 2017). Nevertheless, significant differences in the 479 transformation kinetics of other substances (e.g., MET, SMZ and TMP) could be observed 480 between pre- and post-denitrifying conditions. This indicates that the type of electron donor 481 used for $\mathrm{NO}_{\mathrm{X}}$ reduction influences not only the activity and the community composition of 482 denitrifiers, but also their capacity of biotransforming pharmaceuticals (including structural 483 analogues, e.g. ATN and MET).

484 Parent-to-retransformable chemical ratios in pre-clarified wastewater $\left(n_{L I, C J}\right)$ were estimated 485 for SMX, DCF and MET, indicating (particularly for SMX) comparably high concentration 486 levels of retransformable fractions $\left(C_{C J}\right)$. Values of $n_{L I, C J}$ for SMX were in agreement with 
ratios measured in pre-clarified sewage (Göbel et al., 2007; Plósz et al., 2010b).

488 Overall, DCF was found to be recalcitrant, in agreement with previous evidences from DNAS 489 and DNMBBR, but opposed to what observed in NMBBR (Table 2). In Batch 2, other 490 pharmaceuticals (IBU, IOH, SMZ and VFX) were also found recalcitrant. IBU is known to be 491 rapidly biodegradable in activated sludge under aerobic conditions $\left(k_{b i o}>10 \mathrm{~L} \mathrm{gTSS}^{-1} \mathrm{~d}^{-1}\right.$; Joss 492 et al., 2006).While this has been observed also in NMBBRs (Escolá Casas et al., 2015; Torresi 493 et al., 2016), significant variability in rate constants was shown, whereby also negligible IBU 494 removal was reported (Falås et al., 2012). Reduced biotransformation was also found in DNAS 495 (Suarez et al., 2010) and DNMBBR (Torresi et al., 2017) as compared to aerobic conditions, 496 still significantly higher than in this study. In agreement with our findings, VFX underwent 497 limited degradation both in NMBBR and DNAS (Falås et al., 2013; Escolá Casas et al., 2015; 498 Torresi et al., 2016), while enhanced biotransformation via cometabolism was observed in the 499 presence of methanol or ethanol in DNMBBR (Torresi et al., 2017).

500 A number of differences were found between the two batch experiments. Values of $k_{b i o}$ for 501 TMP and MET significantly decreased in Batch 2, still within the variability of literature rate 502 constants in DNAS and NMBBR (Table 2). Furthermore, tentative results supporting 503 enantioselective ATN biotransformation were found in Batch 1. Assuming that both ATN 504 enantiomers were present also during Batch 2, this may indicate limited enantioselectivity by 505 MBBR biofilm as a result of long-term adaptation. Preferential elimination of the S(-)506 enantiomer of ATN was reported in full-activated sludge WWTPs, whereas limited 507 enantioselectivity was shown in biofilm systems (e.g., trickling filters) (Kasprzyk-Hordern and 508 Baker, 2011). Enantioselective removal of CIT was also considered to explain $E F$ variations 509 between WWTP influent and effluent (MacLeod et al., 2007; Evans et al., 2015). Measured EF 510 ratios in WWTP influents were similar to what estimated in this study for CIT, while 
511 differences were shown for ATN (Table 2).

\subsubsection{Removal efficiency during continuous-flow operation}

515 The removal of pharmaceuticals was also investigated during continuous-flow operation of the

516 single- and three-stage MBBRs, in proximity of Batch 1 and 2. Removal efficiencies in the two 517 systems, calculated from influent and effluent concentrations, are shown in Table S7. Removal 518 efficiencies in each reactor stage (S1, S2 and S3) were calculated for ATN, CIT, TMP and 519 ERY (Fig. S14).

520 Generally, removal efficiencies were in agreement with observations from batch experiments. 521 ATN and CIT underwent relatively high removal in both single- and three-stage MBRRs $(\geq$ $52272 \%$ and 56-67\% respectively), as previously observed in post-denitrifying MBBR (HRT=2 h; 523 Torresi et al., 2017). Intermediate removal efficiencies (25-50\%) were shown for TMP and 524 ERY, also similarly to ethanol- and methanol-dosed post-denitrifying MBBRs, respectively 525 (Torresi et al., 2017). Formation of SMX and DCF was shown, thus resulting in negative 526 removal efficiencies (up to $-157 \%$ ) that are in agreement with findings in full-scale WWTPs 527 (Plósz et al., 2010b, 2012; Göbel et al., 2005, 2007). Substances classified as recalcitrant based 528 on estimated $k_{b i o}$ also exhibited limited elimination (removal efficiency $<10 \%$ ).

529 In the three-stage system, non-recalcitrant and non-retransformable compounds showed highest

530 removal efficiency in S1 (Fig. S14) with the exception of TMP, which underwent the highest 531 removal in S3. Interestingly, differences between Batch 1 and 2 were reflected by changes in 532 removal efficiency. SMX and TMP underwent increased (Batch 1: $-157 \%$ and -135\%; Batch 2: $533-58 \%$ and $-39 \%$ ) and decreased (Batch 1: $39 \%$ and 49\%; Batch 2: $24 \%$ and 29\%) removal 534 efficiency, respectively, in line with changes in estimated $k_{b i o}$ values. 
3.3. Linking denitrification and pharmaceutical biotransformation (Batch 2)

Long-term system operation (>450 d) was instrumental in ensuring sufficient biomass adaptation (Weiss and Reemtsma, 2008), as exemplified by differences between Batch 1 and 2 .

Prolonged exposure to increased organic substrate loading and availability in S1 corresponded to an enhancement of denitrification and biotransformation kinetics. At the same time, biofilm

541 in S1 had access to a broader and more diverse array of carbon sources (including 542 pharmaceuticals), likely including a higher fraction of readily degradable organic substrates. 543 Hence, on the one hand, a more active denitrifying community likely populated the biofilm in 544 S1 compared to S3, which instead included a higher fraction of inert biomass (Boltz et al., 545 2017). This may have led to a positive influence on the cometabolic biotransformation of a 546 number of pharmaceuticals (as further discussed in this paragraph). On the other hand, the 547 exposure to different organic loading resulted in the development of microbial communities 548 with different degree of biodiversity in the three-staged MBBR, possibly influencing 549 pharmaceutical biotransformation. Preliminary results on the influence of reactor staging on 550 microbial community composition in the MBBRs can be found in Torresi (2017).

551 Findings in this study are in analogy with observations in a two-stage managed aquifer 552 recharge system, where carbon availability positively influenced the removal of a number of 553 pharmaceuticals (as well as denitrifying activity) under anoxic conditions (Hellauer et al., 554 2017). Furthermore, increased carbon loading to aerobic activated sludge reactors was 555 beneficial for the removal of estrone (Tan et al., 2013). On the contrary, staging of aerobic 556 MBBRs resulted in an overall enhancement of biotransformation kinetics by substrate-limited 557 biofilms in the last reactor stage (Escolá Casas et al., 2015).

558 The relationship between denitrification and biotransformation kinetics in S1, S2, S3 and U 
559 was further assessed in detail. Figure 5a and S12a present transformation rate constants for all

560 non-recalcitrant pharmaceuticals, i.e. SMX, ERY, TMP, ATN, and CIT, plotted as a function

561 of $\bar{k}_{\text {NOX }}$. Strong linear correlations were shown for SMX, ERY and TMP $\left(\mathrm{R}^{2}=0.90-0.99\right.$; Fig.

562 5a), while weaker correlation was found for ATN and CIT $\left(R^{2}=0.44-0.53\right.$; Fig. S13a).

563 Interestingly, varying regression slopes were shown for the selected pharmaceuticals, possibly

564 indicating significantly different transformation potential by denitrifying communities

565 (independently of the available organic substrate). Linear correlations have been previously

566 observed between $k_{b i o}$ and specific nitrification rates for several pharmaceuticals, including

567 trimethoprim (Fernandez-Fontaina et al., 2012).

568 Similarly, linear correlations were observed between $k_{b i o}, k_{d e c}$ and $\mu_{\max }$ (Fig. 5b) and 1- $Y_{H}$ (Fig.

$5695 \mathrm{c})$, although less strong as compared to $\bar{k}_{N O X}\left(\mathrm{R}^{2}=0.54-0.78\right)$. The correlation obtained with

$570 \mu_{\max }$ supports reasonably well the positive relationship between kinetics of denitrification and

571 pharmaceutical biotransformation. The parameter $1-Y_{H}$ denotes the fraction of electron

572 equivalents used for catabolic respiration (thus, $\mathrm{NO}_{\mathrm{X}}$ reduction). Accordingly, the utilization of

573 organic substrate for storage and/or anabolism negatively influenced the removal of

574 pharmaceuticals, thus further suggesting the association biotransformation with denitrifying

575 activity. Taken together, these observations point towards the conclusion that

576 biotransformation of non-recalcitrant pharmaceuticals resulted from cometabolism by

577 denitrifying bacteria. Simultaneous increased loading and availability of organic substrate, as

578 induced in reactor S1, can result in a significant enhancement of both heterotrophic

579 denitrification and pharmaceutical biotransformation capacity as compared to single-stage

580 systems and reactors operated under substrate-limited conditions.

581 Considering the positive dependency with heterotrophic denitrification, a cometabolic 582 biotransformation model was proposed based on the correlations in Fig. 5a (Eq. 10): 
$583 \quad \frac{d C_{L I}}{d t}=T_{C, N O X} \bar{k}_{N O X} C_{L I}$

584 The coefficient $T_{C, N O X}\left(\mathrm{~L} \mathrm{mgN}^{-1}\right.$; Eq. 11):

$585 T_{C, N O X}=\frac{k_{b i o, d e c}}{\bar{k}_{N O X}}$

586 is defined as the transformation coefficient associated to denitrification, and quantifies the

587 relative pharmaceutical mass (-) transformed per $\mathrm{mgN} \mathrm{L}^{-1}$ reduced. $T_{C, N O X}$ was defined in 588 analogy to coefficients relating kinetics of pharmaceutical transformation and of ammonia 589 oxidation (Sathyamoorthy et al., 2013). Interestingly, selected pharmaceuticals exhibited a 590 wide range of $T_{C, N O X}$ values $\left(0.005-0.072 \mathrm{~L} \mathrm{mgN}^{-1}\right)$, indicating significantly different 591 transformation potential by denitrifying communities (independently of the available organic 592 substrate). The presented model represents one of the first attempts to describe cometabolic 593 biodegradation under pre-denitrifying conditions, and can be used for forward predictions of 594 pharmaceutical removal as a function of denitrifying activity. Nevertheless, this approach 595 requires further confirmation through validation with independent datasets. 


\section{Conclusions}

599 Based on the experimental (continuous-flow monitoring, batch experiments) and model-based 600 observations presented in this study, we could draw the following conclusions:

601 - Reactor staging effectively determined a gradient in organic substrate loading and 602 availability in the three-stage pre-denitrifying MBBR. Fluctuations in influent composition 603 led to not negligible dynamics in the denitrification performance during continuous-flow 604 operation, with an overall decrease of denitrification rates after 400 days of operation.

- Retransformation from conjugated metabolites led to the formation of parent sulfonamide 606 antibiotics, namely sulfamethoxazole and sulfadiazine. Possible enantioselective 607 biotransformation was observed for atenolol and citalopram, and a model was developed 608 and successfully calibrated to describe observed removal kinetics.

609 - As compared to previous findings for nitrifying MBBR and denitrifying activated sludge, 610 enhanced biotransformation kinetics were shown for sulfamethoxazole, erythromycin and 611 atenolol, in particular at higher organic substrate availability. Hence, pre-denitrifying 612 MBBRs operated under increased organic substrate availability may represent a valid 613 option to improve the removal of these three pharmaceuticals.

614 - Tiered organic substrate loading and quality in single-stage and three-stage MBBRs 615 determined significant differences in the microbial community functions of denitrification 616 and pharmaceutical biotransformation. After more than 450 days of continuous-flow 617 operation, the highest denitrification and pharmaceutical biotransformation kinetics were 618 shown in reactor $\mathrm{S} 1$, exposed to the highest electron donor loading and availability.

619 - When considering all MBBRs, biotransformation rate constants of non-recalcitrant 620 pharmaceuticals positively correlated with mean specific denitrification rates, maximum 621 specific growth rates and catabolic electron fractions. This indicates that biotransformation 
of pharmaceuticals is likely a cometabolic process, and that microbial activity both in terms of primary (denitrification) and secondary (pharmaceutical biotransformation) metabolic processes activity is more effectively supported by non-limiting organic substrate availability.

\section{Acknowledgments}

628 F. Polesel acknowledges financial support from the Technical University of Denmark (DTU),

Department of Environmental Engineering for a $\mathrm{PhD}$ research fellowship. This research was also supported by MERMAID, ITN funded by the People Programme (Marie Skłodowska631 Curie Actions) of the EU FP7/2007-2013/ under REA grant agreement $\mathrm{n}^{\circ}$ 607492', and by the 632 AUFF Center for Advanced Water Purification. The authors are grateful to Carlos Domingo633 Félez for scientific discussion and to Mona Refstrup for the support with chemical analyses.

\section{References}

636 Alder, A.C., Schaffner, C., Majewsky, M., Klasmeier, J., Fenner, K. (2010). Fate of $\beta$-blocker 637 human pharmaceuticals in surface water: Comparison of measured and simulated 638 concentrations in the Glatt Valley Watershed, Switzerland. Water Res. 44, 936-948.

639 Bendz, D., Paxeus, N.A., Ginn, T.R., Loge, F.J. (2005). Occurrence and fate of 640 pharmaceutically active compounds in the environment, a case study: Höje River in 641 Sweden. J. Hazard. Mater. 122, 195-204.

642 Beun, J.J., Verhoef, E.V., van Loosdrecht, M.C.M., Heijnen, J.J. (2000). Stoichiometry and 643 kinetics of poly- $\beta$-hydroxybutyrate metabolism under denitrifying conditions in activated 644 sludge cultures. Biotechnol. Bioeng. 68, 496-507.

645 Boltz, J.P., Johnson, B.R., Takács, I., Daigger, G.T., Morgenroth, E., Brockmann, D., Kovács, 
646 R., Calhoun, J.M., Choubert, J.M., Derlon, N. (2017). Biofilm carrier migration model 647 describes reactor performance. Water Sci. Technol., accepted, doi: 10.2166/wst.2017.160

648 Clesceri, L.S., Greenberg, A.E., Eaton, A.D. (1998). Standard Methods for the Examination of 649 Water and Wastewater (20 ${ }^{\text {th }}$ edition). APHA, Washington, US.

650 Collado, N., Buttiglieri, G., Ferrando-Climent, L., Rodriguez-Mozaz, S., Barceló, D., Comas, 651 J., Rodriguez-Roda, I. (2012). Removal of ibuprofen and its transformation products: 652 Experimental and simulation studies. Sci. Total Environ. 433, 296-301.

653 de Graaff, M.S., Vieno, N.M., Kujawa-Roeleveld, K., Zeeman, G., Temmink, H., Buisman, 654 C.J.N. (2011). Fate of hormones and pharmaceuticals during combined anaerobic treatment 655 and nitrogen removal by partial nitritation-anammox in vacuum collected black water. $656 \quad$ Water Res. 45, 375-383.

657 Ekama, G.A., Wentzel, M.C. (1999). Denitrification kinetics in biological N and P removal 658 activated sludge systems treating municipal wastewaters. Water Sci. Technol. 39, 69-77.

659 Ekama, G.A., Wentzel, M.C. (2008). Nitrogen removal. In Henze, M., van Loosdrecht, 660 M.C.M., Ekama, G., Brdjanovic, D., "Biological wastewater treatment-principles, 661 modelling and design", IWA Publishing, London, UK.

662 Escher, B.I., Bramaz, N., Richter, M., Lienert, J. (2006). Comparative ecotoxicological hazard 663 assessment of beta-blockers and their human metabolites using a mode-of-action-based test 664 battery and a QSAR approach. Environ. Sci. Technol. 40, 7402-7408.

665 Escolá Casas, M., Chhetri, R.K., Ooi, G., Hansen, K.M.S., Litty, K., Christensson, M., 666 Kragelund, C., Andersen, H.R., Bester, K. (2015). Biodegradation of pharmaceuticals in 667 hospital wastewater by staged Moving Bed Biofilm Reactors (MBBR). Water Res. 83, 293$668 \quad 302$.

669 Evans, S. E., Davies, P., Lubben, A., Kasprzyk-Hordern, B. (2015) Determination of chiral 
670 pharmaceuticals and illicit drugs in wastewater and sludge using microwave assisted 671 extraction, solid-phase extraction and chiral liquid chromatography coupled with tandem 672 mass spectrometry. Anal. Chim. Acta 882, 112-126.

673 Falås, P., Baillon-Dhumez, A., Andersen, H.R., Ledin, A., la Cour Jansen, J. (2012). 674 Suspended biofilm carrier and activated sludge removal of acidic pharmaceuticals. Water $675 \quad$ Res. $46,1167-1175$.

676 Falås, P., Longrée, P., la Cour Jansen, J., Siegrist, H., Hollender, J., Joss, A. (2013). 677 Micropollutant removal by attached and suspended growth in a hybrid biofilm-activated 678 sludge process. Water Res. 47, 4498-4506.

679 Fernandez-Fontaina, E., Omil, F., Lema, J.M., Carballa, M. (2012). Influence of nitrifying 680 conditions on the biodegradation and sorption of emerging micropollutants. Water Res. 46, $681 \quad 5434-5444$.

682 Ghattas, A.K., Fischer, F., Wick, A., Ternes, T. (2017). Anaerobic biodegradation of 683 (emerging) organic contaminants in the aquatic environment. Water Res., accepted.

684 Göbel, A., Thomsen, A., McArdell, C.S., Joss, A., Giger, W. (2005). Occurrence and sorption 685 behavior of sulfonamides, macrolides, and trimethoprim in activated sludge treatment. 686 Environ. Sci. Technol. 39, 3981-3989.

687 Göbel, A., McArdell, C.S., Joss, A., Siegrist, H., Giger, W. (2007). Fate of sulphonamides, 688 macrolides, and trimethoprim in different wastewater technologies. Sci. Total Environ., 372, $689 \quad 361-371$.

690 Grady, Jr., C.P.L., Daigger, G.T., Love, N.G., Filipe, C.D.M. (2011). Biological Wastewater 691 Treatment ( $3^{\text {rd }}$ edition). IWA Publishing, London, UK.

692 Hellauer, K., Mergel, D., Ruhl, A.S., Filter, J., Hübner, U., Jekel, M., Drewes, J.E. (2017). 693 Advancing sequential managed aquifer recharge technology (SMART) using different 
694 intermediate oxidation processes. Water 9, 221.

695 Hörsing, M., Ledin, A., Grabic, R., Fick, J., Tysklind, M., la Cour Jansen, J., Andersen, H.R. 696 (2011). Determination of sorption of seventy-five pharmaceuticals in sewage sludge. Water 697 Res. 45, 4470-4482.

698 Jelic, A., Gros, M., Ginebreda, A., Cespedes-Sánchez, R., Ventura, F., Petrovic, M., Barceló, 699 D. (2011). Occurrence, partition and removal of pharmaceuticals in sewage water and 700 sludge during wastewater treatment. Water Res. 45, 1165-1176.

701 Jewell, K.S., Castronovo, S., Wick, A., Falås, P., Joss, A., Ternes, T.A. (2016). New insights 702 into the transformation of trimethoprim during biological wastewater treatment. Water Res. $703 \quad 88,550-557$.

704 Joss, A., Zabczynski, S., Göbel, A., Hoffmann, B., Löffler, D., McArdell, C.S., Ternes, T.A., 705 Thomsen, A., Siegrist, H. (2006). Biological degradation of pharmaceuticals in municipal 706 wastewater treatment: Proposing a classification scheme. Water Res. 40, 1686-1696.

707 Kasprzyk-Hordern, B., Baker, D.R. (2011). Enantiomeric profiling of chiral drugs in 708 wastewater and receiving waters. Environ. Sci. Technol. 46, 1681-1691.

709 Kujawa, K., Klapwijk, B. (1999) A method to estimate denitrification potential for 710 predenitrification systems using NUR batch test. Water Res. 33, 2291-2300.

711 Lee, H.J., Lee, E., Yoon, S.H., Chang H.R., Kim, K., Kwon, J.H. (2012). Enzymatic and 712 microbial transformation assays for the evaluation of the environmental fate of diclofenac 713 and its metabolites. Chemosphere 87, 969-974.

714 MacLeod, S.L., Sudhir, P., Wong, C.S. (2007). Stereoisomer analysis of wastewater-derived $\beta$ 715 blockers, selective serotonin re-uptake inhibitors, and salbutamol by high-performance 716 liquid chromatography-tandem mass spectrometry. J. Chromatogr. A 1170, 23-33.

717 Maurer, M., Escher, B.I., Richle, P., Schaffner, C., Alder, A.C. (2007). Elimination of $\beta$ - 
718 blockers in sewage treatment plants. Water Res. 41, 1614-1622.

719 Muller, A., Wentzel, M.C., Loewenthal, R.E., Ekama, G.A. (2003). Heterotroph anoxic yield in 720 anoxic aerobic activated sludge systems treating municipal wastewater. Water Res. 37, $721 \quad 2435-2441$.

722 Nikolai, L.N., McClure, E.L., MacLeod, S.L., Wong, C.S. (2006). Stereoisomer quantification 723 of the $\beta$-blocker drugs atenolol, metoprolol, and propranolol in wastewaters by chiral high724 performance liquid chromatography-tandem mass spectrometry. J. Chromatogr. A 1131, $725 \quad 103-109$.

726 Pan, Y., Ni, B.J., Lu, H., Chandran, K., Richardson, D., Yuan, Z. (2015). Evaluating two 727 concepts for the modelling of intermediates accumulation during biological denitrification 728 in wastewater treatment. Water Res. 71, 21-31.

729 Plósz, B.G. (2007). Optimization of the activated sludge anoxic reactor configuration as a 730 means to control nutrient removal kinetically. Water Res. 41, 1763-1773.

731 Plósz, B.G., Vogelsang, C., Macrae, K., Heiaas, H.H., Lopez, A., Liltved, H., Langford, K.H. 732 (2010a). The BIOZO process - a biofilm system combined with ozonation: occurrence of 733 xenobiotic organic micro-pollutants in and removal of polycyclic aromatic hydrocarbons 734 and nitrogen from landfill leachate. Water Sci. Technol. 61, 3188-3197.

735 Plósz, B.G., Leknes, H., Thomas, K.V. (2010b). Impacts of competitive inhibition, parent 736 compound formation and partitioning behaviour on antibiotic micro-pollutants removal in 737 activated sludge. Environ. Sci. Technol., 44, 734-742.

738 Plósz, B.G., Langford, K.H., Thomas, K.V. (2012). An activated sludge model for trace 739 xenobiotic chemicals (ASM-X): Assessment of diclofenac and carbamazepine. Biotechnol. $740 \quad$ Bioeng., 109, 2757-2769.

741 Plósz, B.G., Reid, M.J, Borup, M., Langford, K.H., Thomas, K.V. (2013). Biotransformation 
kinetics and sorption of cocaine and its metabolites and the factors influencing their estimation in wastewater. Water Res., 47, 2129-2140.

744 Polesel, F., Andersen, H.R., Trapp, S., Plósz, B.G. (2016). Removal of antibiotics in biological

Radjenovic, J., Petrovic, M., Barceló, D. (2009). Fate and distribution of pharmaceuticals in wastewater treatment systems-A critical assessment using the Activated Sludge Modeling Framework for Xenobiotics (ASM-X). Environ. Sci. Technol. 50, 10316-10334. wastewater and sewage sludge of the conventional activated sludge (CAS) and advanced membrane bioreactor (MBR) treatment. Water Res. 43, 831-841.

Radke, M., Lauwigi, C., Heinkele, G., Mürdter, T.E., Letzel, M. (2009). Fate of the antibiotic sulfamethoxazole and its two major human metabolites in a water sediment test. Environ. Sci. Technol. 43, 3135-3141.

Reichert, P. (1998). AQUASIM 2.0—Computer Program for the Identification and Simulation of Aquatic Systems. EAWAG, Dübendorf, Switzerland.

Ribeiro, A.R., Afonso, C.M., Castro, P.M.L., Tiritan, M.E. (2013). Enantioselective HPLC analysis and biodegradation of atenolol, metoprolol and fluoxetine. Environ. Chem. Lett. $11,83-90$.

Roeleveld, P.J., van Loosdrecht, M.C.M. (2002). Experience with guidelines for wastewater characterisation in The Netherlands. Water Sci. Technol. 45, 77-87.

Sathyamoorthy, S., Chandran, K., Ramsburg, C.A. (2013). Biodegradation and cometabolic modeling of selected beta blockers during ammonia oxidation. Environ. Sci. Technol. 47, $12835-12843$.

763 Scuras, S.E., Jobbágy, A., Grady, Jr., C.P.L. (2001). Optimization of activated sludge reactor 764 configuration: kinetic considerations. Water Res. 35, 4277-4284.

765 Stadler, L.B., Su, L., Moline, C.J., Ernstoff, A.S., Aga, D.S., Love, N.G. (2015). Effect of 
redox conditions on pharmaceutical loss during biological wastewater treatment using sequencing batch reactors. J. Hazard. Mater. 282, 106-115.

Stierlin, H., Faigle, J.W. (1979). Biotransformation of diclofenac sodium (Voltaren®) in

Su, L., Aga, D., Chandran, K., Khunjar, W.O. (2015). Factors impacting biotransformation phenolic metabolites, in urine and bile. Xenob. 9, 611-621. kinetics of trace organic compounds in lab-scale activated sludge systems performing nitrification and denitrification. J. Hazard. Mater. 281, 116-124.

Suarez, S., Lema, J.M., Omil, F. (2010). Removal of Pharmaceutical and Personal Care Products (PPCPs) under nitrifying and denitrifying conditions. Water Res. 44, 3214-3224.

Tan, D.T., Arnold, W.A., Novak, P.J. (2013). Impact of organic carbon on the biodegradation of estrone in mixed culture systems. Environ. Sci. Technol. 47, 12359-12365.

Ternes, T.A., Herrmann, N., Bonerz, M., Knacker, T., Siegrist, H., Joss, A. (2004). A rapid method to measure the solid-water distribution coefficient $\left(\mathrm{K}_{\mathrm{d}}\right)$ for pharmaceuticals and musk fragrances in sewage sludge. Water Res. 38, 4075-4084.

Torresi, E., Fowler, S.J., Polesel, F., Bester, K., Andersen, H.R., Smets, B.F., Plósz, B.G., Christensson, M. (2016). Biofilm thickness influences biodiversity in nitrifying MBBRs Implications on micropollutant removal. Environ. Sci. Technol. 50, 9279-9288.

Torresi, E., Escolá Casas, M., Polesel, F., Plósz, B.G., Christensson, M., Bester, K. (2017). Impact of external carbon dose on the removal of micropollutants using methanol and ethanol in post-denitrifying Moving Bed Biofilm Reactors. Water Res. 108, 95-105.

Torresi, E. (2017). Removal of micropollutants in Moving Bed Biofilm reactors (MBBRs) Microbial structure and function relationships. PhD dissertation, DTU Environment, Technical University of Denmark. 
790 Ubay Çokgör, E., Sözen, S., Orhon, D., Henze, M. (1998). Respirometric analysis of activated 791 sludge behaviour-I. Assessment of the readily biodegradable substrate. Water Res. 32, $792 \quad 461-475$.

793 van der Ven, A.J.A.M., Vree, T.B., van Ewijk-Beneken Kolmer, E.W.J., Koopmans, P.P., van 794 der Meer, J.W.M. (1995). Urinary recovery and kinetics of sulphamethoxazole and its 795 metabolites in HIV-seropositive patients and healthy volunteers after a single oral dose of 796 sulphamethoxazole. Br. J. Clin. Pharmac. 39, 621-625.

797 Vazquez-Roig, P., Kasprzyk-Hordern, B., Blasco, C., Picó, Y. (2014). Stereoisomeric profiling 798 of drugs of abuse and pharmaceuticals in wastewaters of Valencia (Spain). Sci. Total 799 Environ. 494-495, 49-57.

800 Vieno, N., Sillanpää, M. (2014). Fate of diclofenac in municipal wastewater treatment-A 801 review. Environ. Intern. 69, 28-39.

802 Vree, T.B., Hekster, Y.A. (1987). Clinical pharmacokinetics of sulfonamides and their 803 metabolites - An encyclopedia. Antibiot. Chemother. 37, 1-214.

804 Vree T.B., van der Ven, A.J.A.M., Koopmans, P.P., van Ewijk-Beneken Kolmer, E.W.J., 805 Verwey-van Wissen, C.P.W.G.M. (1995). Pharmacokinetics of sulfamethoxazole with its 806 hydroxy metabolites and N4-acetyl-, N1-glucuronide conjugates in healthy human 807 volunteers. Clin. Drug Invest. 9, 43-53.

808 Weiss, S., Reemtsma, T. (2008). Membrane bioreactors for municipal wastewater treatment 809 A viable option to reduce the amount of polar pollutants discharged into surface waters? $810 \quad$ Water Res. 42, 3837-3847.

811 Wick, A., Fink, G., Joss, A., Siegrist, H., Ternes, T.A. (2009). Fate of beta blockers and 812 psycho-active drugs in conventional wastewater treatment. Water Res. 43, 1060-1074.

813 Zhang, Y., Geißen, S.U., Gal, C. (2008). Carbamazepine and diclofenac: Removal in 
814 wastewater treatment plants and occurrence in water bodies. Chemosphere 73, 1151-1161.

815 Ødegaard, H., Rusten, B., Westrum, T. (1994). A new moving bed bofilm reactor816 Applications and results. Water Sci. Tech., 29, 157-165.

817 
Table 1. Summary of model structures identified and used in this study to describe pharmaceutical concentration profiles observed during batch experiments (Batch 1 and 2).

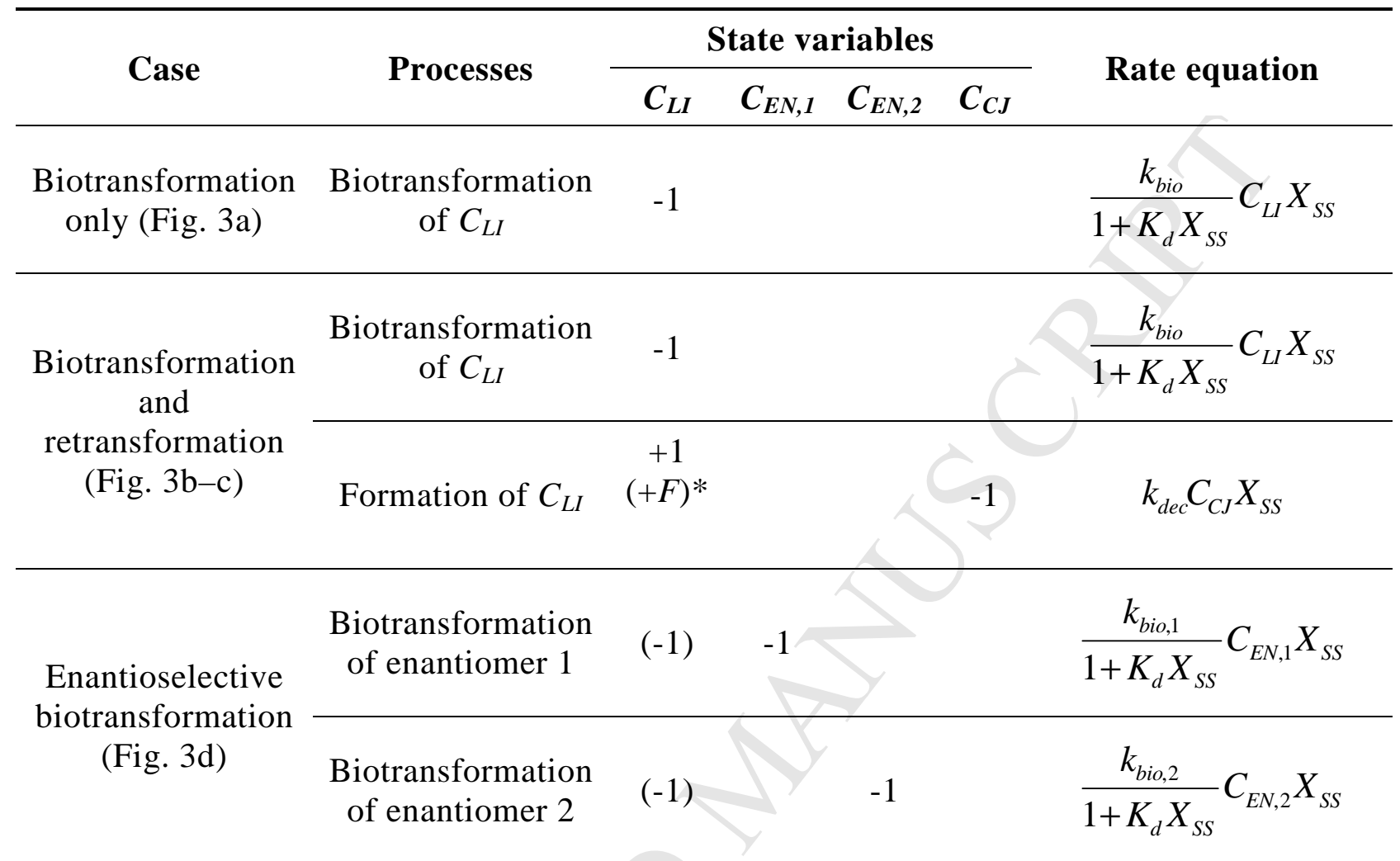

*In case the pharmaceutical has only one known retransformable conjugate (SDZ and AcSDZ), the stoichiometry coefficient $F$ should be used, being equivalent to the ratio of the molecular weight of parent $\left(M_{L I}\right)$ and conjugated $\left(M_{C J}\right)$ pharmaceutical. 
Table 2. Summary of kinetic $\left(k_{b i o}, k_{d e c}, k_{b i o, 1}, k_{b i o, 2}\right.$ in $\left.\mathrm{L} \mathrm{gTSS}^{-1} \mathrm{~d}^{-1}\right)$ and stoichiometric $(E F-$ including the two respective fraction of enantiomer 1 and 2 -and $n_{L I, C J}$ ) parameters estimated in this study on pharmaceutical biotransformation and comparison with literature values.

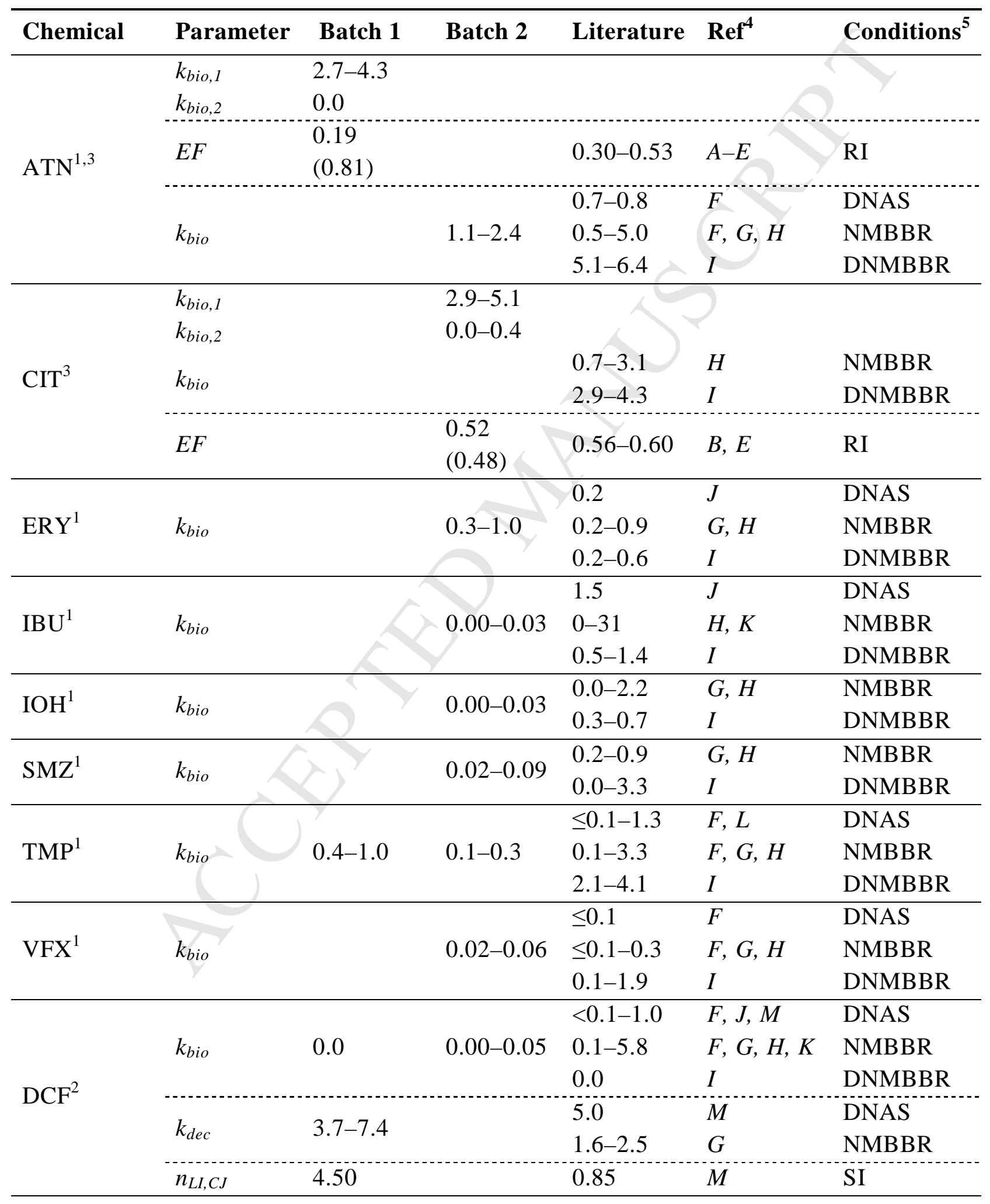




\begin{tabular}{|c|c|c|c|c|c|c|}
\hline \multirow{5}{*}{$\mathrm{MET}^{2}$} & & & & $\leq 0.1$ & $F$ & DNAS \\
\hline & $k_{\text {bio }}$ & $0.1-0.3$ & 0.0 & $0.3-1.2$ & $F, G, H$ & NMBBR \\
\hline & & & & $0.4-0.8$ & $I$ & DNMBBR \\
\hline & $k_{d e c}$ & $0.5-2.4$ & & & & \\
\hline & $n_{L I, C J}$ & 3.80 & & & & \\
\hline \multirow{6}{*}{$\mathrm{SMX}^{2}$} & & & & 0.4 & $N$ & DNAS \\
\hline & $k_{\text {bio }}$ & $0.7-2.2$ & $1.0-3.5$ & $0.2-1.0$ & $G, H$ & NMBBR \\
\hline & & & & $0.1-3.2$ & $I$ & DMBBR \\
\hline & $l_{-}$ & 1065 & 051 & $1.1-7.9$ & $F, N$ & DNAS \\
\hline & $\kappa_{d e c}$ & $1.9-0.5$ & $0.5-2.1$ & $0.7-1.6$ & $F$ & NMBBR \\
\hline & $n_{L I, C J}$ & 0.73 & 0.15 & $0.13-0.66$ & $N, O$ & SI \\
\hline \multirow{4}{*}{$\begin{array}{l}\mathrm{SDZ}^{2} \\
(\mathrm{Ac}-\mathrm{SDZ})\end{array}$} & $k_{1}$. & $07-17$ & & $0.1-0.7$ & $G, H$ & NMBBR \\
\hline & $\kappa_{\text {bio }}$ & $0.1-1.1$ & & $0.6-1.0$ & $I$ & DNMBBR \\
\hline & $k_{1}$ & $10-20$ & & $<0.1-8.4$ & $G, H$ & NMBBR \\
\hline & $\kappa_{d e c}$ & $1.0-2.0$ & & $3.7-4.2$ & & DNMBBR \\
\hline
\end{tabular}

${ }^{1}$ Biotransformation only (Eq. 3); ${ }^{2}$ Bio- and retransformation (Eqs. 4-6); ${ }^{3}$ Enantioselective biotransformation (Eq. 9-10); ${ }^{4}$ References: A=Nikolai et al. (2006); B=MacLeod et al. (2007); $\mathrm{C}=$ Kasprzyk-Hordern and Baker (2011); D=Vazquez-Roig et al. (2014); E=Evans et al. (2015); $\mathrm{F}=$ Falås et al. (2013) (rate constants as $\mathrm{L} \mathrm{gTAS}^{-1} \mathrm{~d}^{-1}$ ); $\mathrm{G}=$ Torresi et al. (2016) (rate constants as $\mathrm{L}$ gTAS d $^{-1}$ ); H=Escolá-Casas et al. (2015) (rate constants as $\mathrm{L}_{\text {gTAS d }}{ }^{-1}$ ); I=Torresi et al. (2017) (rate constants as $\mathrm{L} \mathrm{gTAS} \mathrm{d}^{-1}$ ); $\mathrm{J}=$ Suarez et al. (2010) (rate constants as $\mathrm{L} \mathrm{gVSS}^{-1} \mathrm{~d}^{-1}$ ); K=Falås et al. (2012) (rate constants as $\mathrm{L} \mathrm{gTAS}^{-1} \mathrm{~d}^{-1}$ ); $\mathrm{L}=\mathrm{Su}$ et al. (2015) (rate constants as $\mathrm{L} \mathrm{gCOD}^{-1} \mathrm{~d}^{-1}$ ); $\mathrm{M}=\mathrm{Plósz}$ et al. (2012) (rate constants as $\mathrm{L} \mathrm{gTSS}^{-1} \mathrm{~d}^{-1}$ ); $\mathrm{N}=$ Plósz et al. (2010b) (rate constants as $\mathrm{L} \mathrm{gTSS}^{-1} \mathrm{~d}^{-1}$ ); $\mathrm{O}=$ Göbel et al. (2007); ${ }^{5}$ Abbreviations: DNAS=Denitrifying Activated Sludge; NMBBR=Nitrifying MBBR; DNMBBR=Denitrifying MBBR; RI=Raw Influent; SI=Secondary Influent. 


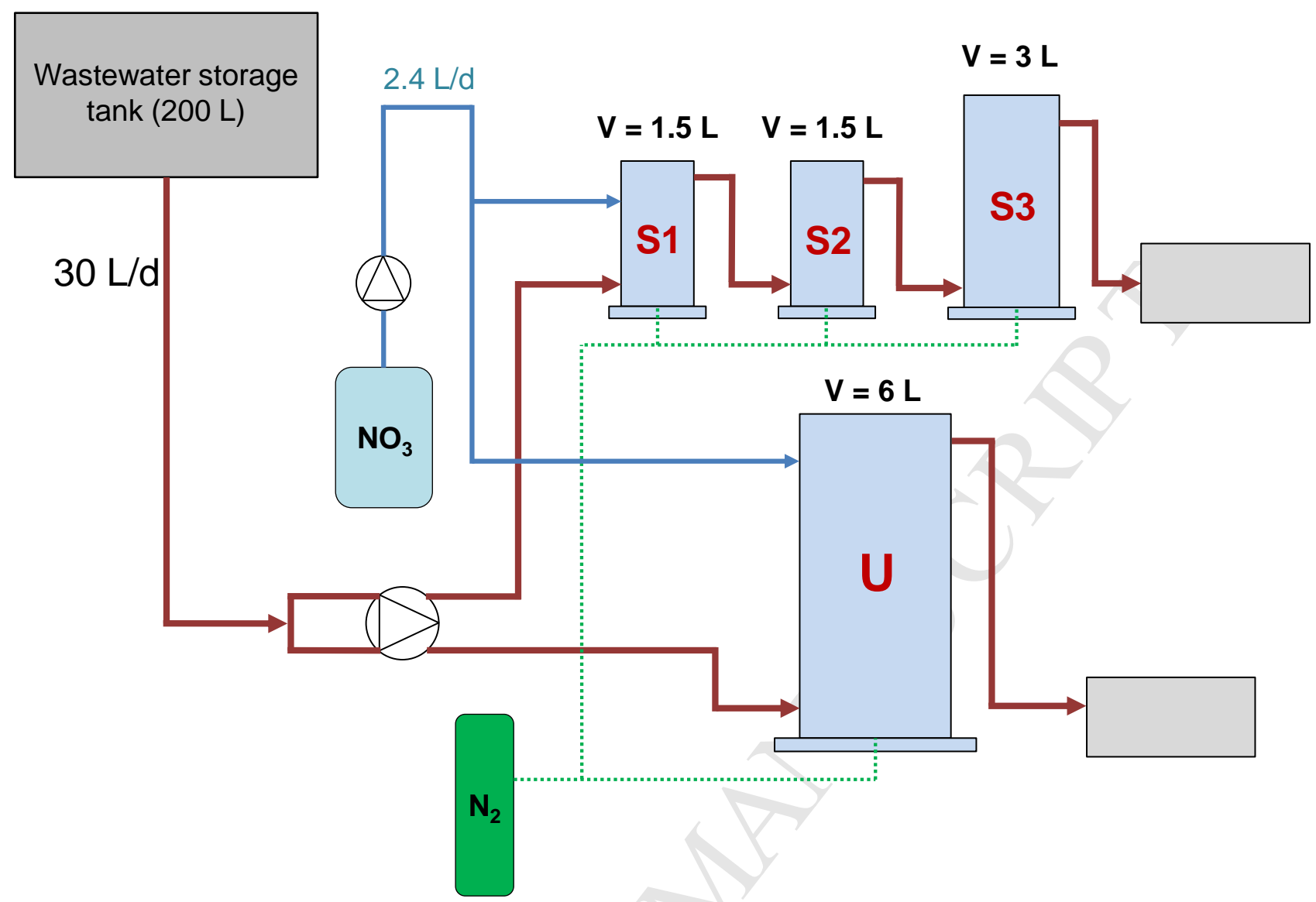

Figure 1. Schematic representation of three-stage (S1, S2, S3) and single-stage (U) MBBR systems under continuous-flow operation. The two MBBRs, having overall the same filling ratio $(33 \%)$ and working volume $(6 \mathrm{~L})$, were operated in parallel with the same influent flow rate $\left(16.2 \mathrm{~L} \mathrm{~d}^{-1}\right)$ and thus the same hydraulic residence time (HRT=8.9 h). External dosing of potassium nitrate $\left(\mathrm{KNO}_{3}\right)$ was performed to achieve an influent $\mathrm{NO}_{3}-\mathrm{N}$ concentration of 103 $\mathrm{mgN} \mathrm{L}^{-1}$ in $\mathrm{S} 1$ and $\mathrm{U}$ reactors. Sparging of $\mathrm{N}_{2}$ gas was used in each MBBR to minimize oxygen penetration and ensure carrier mixing in the reactors. 

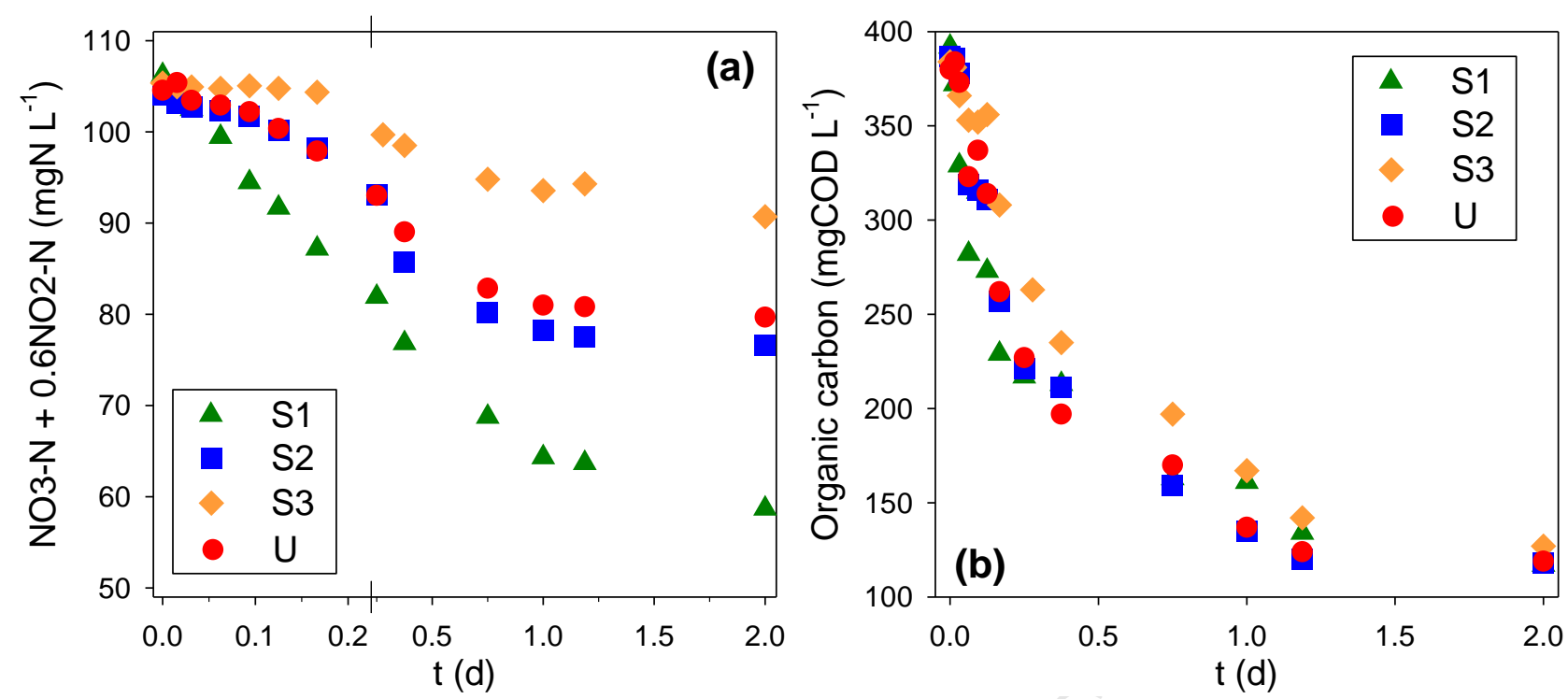

Figure 2. Concentration profiles of $\mathrm{NO}_{\mathrm{X}}$ (a) and total COD (b) measured during anoxic respirometry (Batch 2) in different MBBR reactors. The $x$-axis in (a) is intentionally subdivided in two parts of different scales to highlight lag phases in $\mathrm{NO}_{\mathrm{X}}$ reduction in $\mathrm{S} 2, \mathrm{U}$ and S3. 

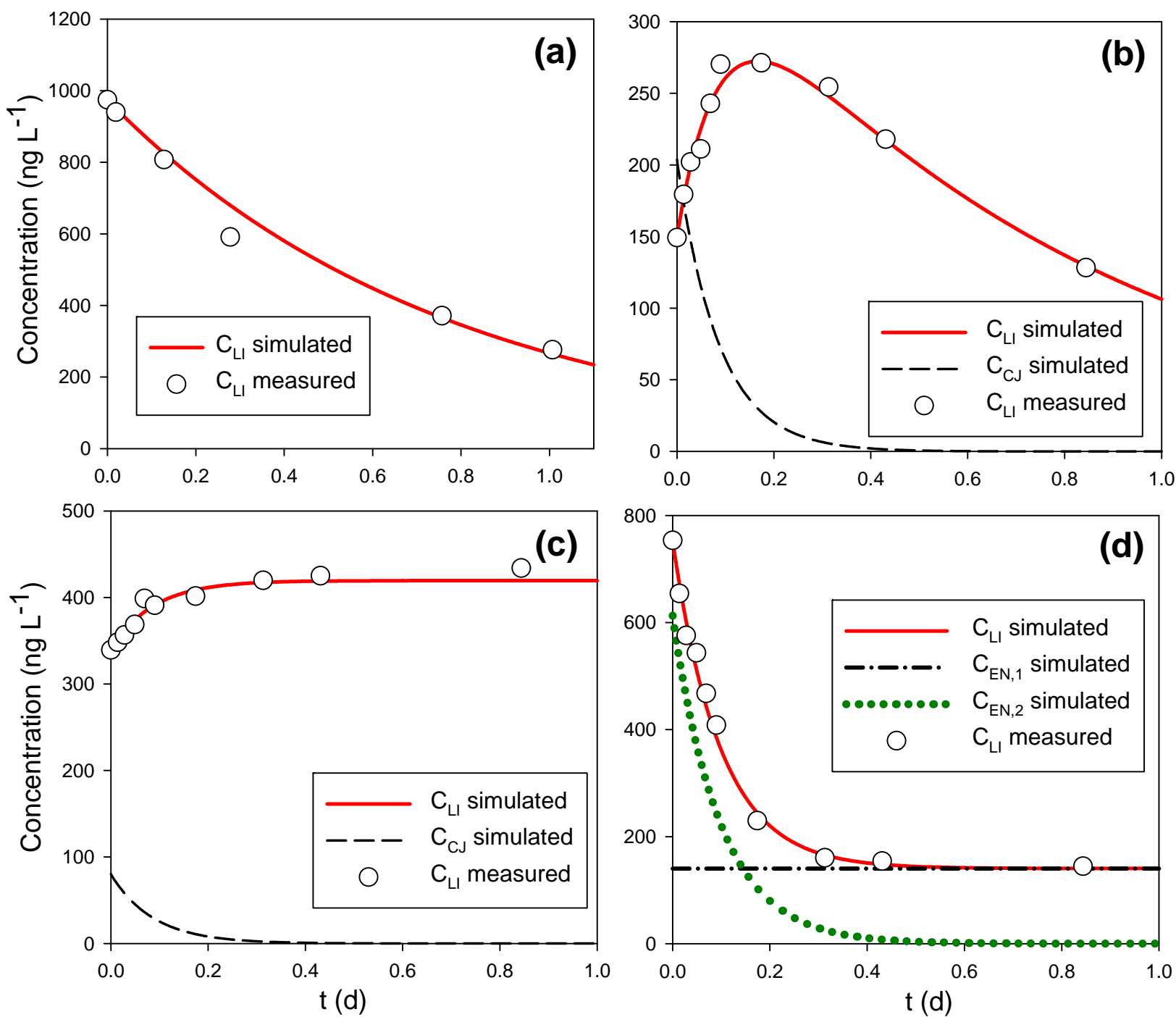

Figure 3. Typical profiles of pharmaceutical concentrations observed during batch experiments (circles) and simulation results with calibrated model (full, dashed and dotted lines): (a) biotransformation only (ATN, Batch 2; Eq. 3); (b, c) retransformation and biotransformation (b: SMX, Batch 1; c: DCF, Batch 1; Eq. 5-6); (d) enantioselective biotransformation (ATN, Batch 1; Eq. 9). 


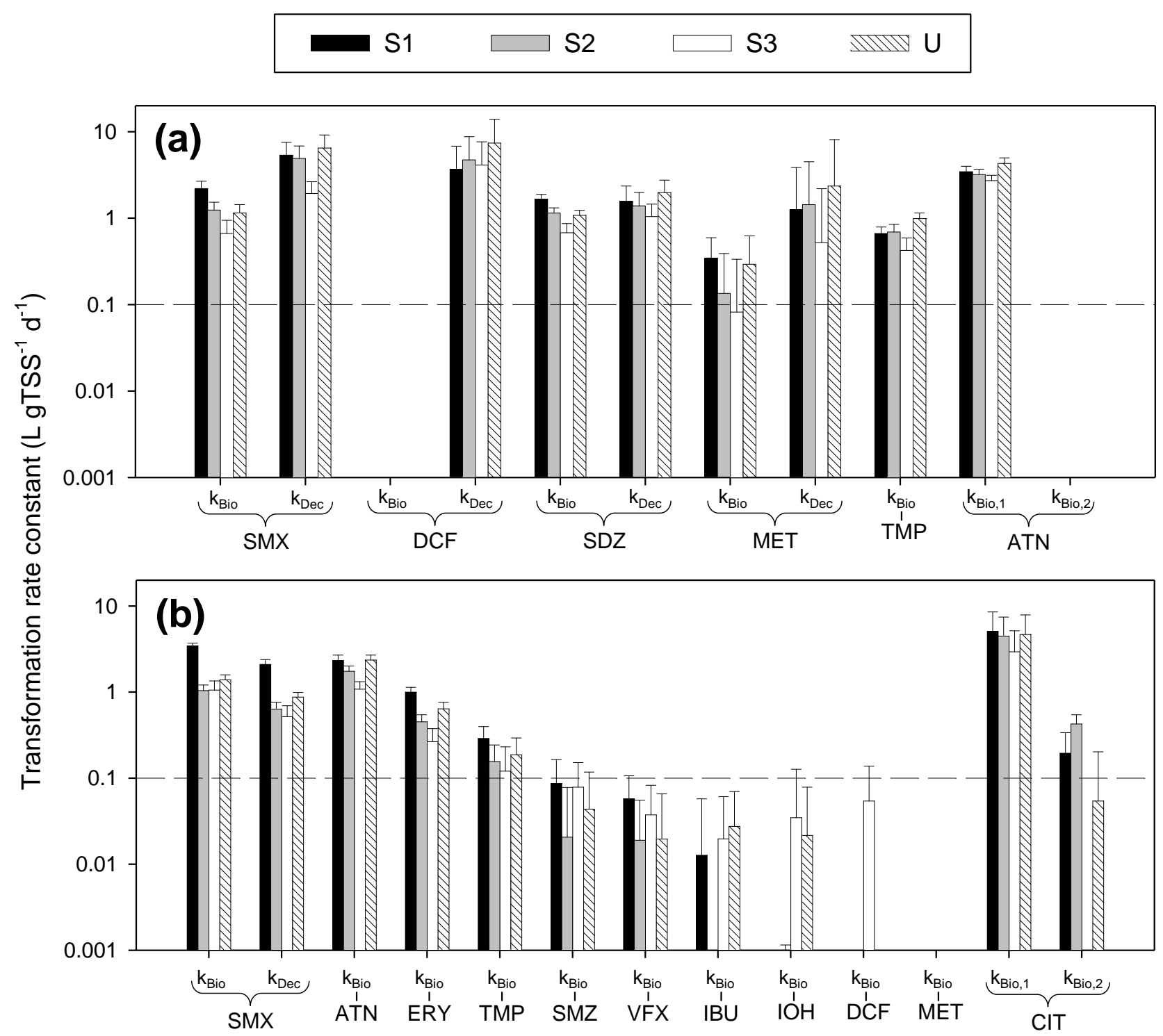

Figure 4. Estimated transformation rate constants for pharmaceuticals in Batch 1 (a) and Batch 2 (b). The dashed line at $k_{\text {bio }}=0.1 \mathrm{~L} \mathrm{gTSS}^{-1} \mathrm{~d}^{-1}$ (Joss et al., 2006) is used as threshold to identify recalcitrant and non-recalcitrant pharmaceuticals. 

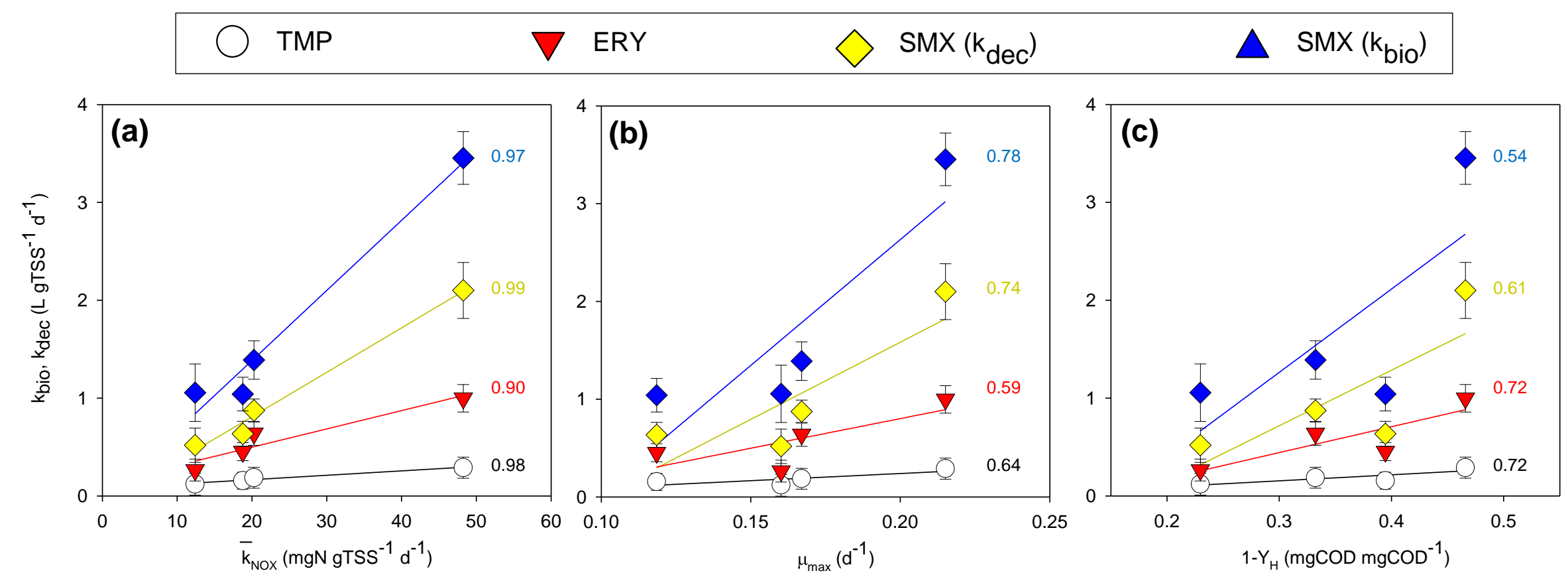

Figure 5. Estimated transformation rate constants $\left(k_{b i o}, k_{d e c}\right)$ for non-recalcitrant pharmaceuticals plotted as a function of (a) mean specific denitrification rate $\left(\bar{k}_{N O X}\right)$, (b) maximum specific growth rate $\left(\mu_{\max }\right)$ and (c) catabolic electron fraction $\left(1-Y_{H}\right)$ during Batch 2 in different MBBR reactors (S1, S2, S3, U). Linear regressions (solid lines) are used to indicate the possible correlation between denitrification and pharmaceutical removal kinetics for each substance (numbers in the figure denote the $\mathrm{R}^{2}$ values of each regression). 


\section{Highlights}

- Staging of pre-denitrifying MBBR induced tiered organic substrate availability

- Biotransformation of pharmaceuticals assessed in single- and three-stage MBBRs

- Improved denitrification and biotransformation shown at higher carbon availability

- Pharmaceutical biotransformation and denitrifiying activity positively correlated

- Cometabolic biotransformation model associated to denitrification is proposed 